\title{
Disentangling Civilian and Military Spending Shocks: A Bayesian DSGE Approach for the US Economy
}

\author{
Marco Lorusso ${ }^{1, *}$ and Luca Pieroni ${ }^{2}$ \\ 1 Newcastle Business School, Northumbria University, Newcastle upon Tyne NE18ST, UK \\ 2 Department of Political Science, University of Perugia, 06123 Perugia PG, Italy \\ * Correspondence: marco.lorusso@northumbria.ac.uk; Tel.: +44-(0)191-349-5803
}

Received: 8 August 2019; Accepted: 22 August 2019; Published: 1 September 2019

\begin{abstract}
In this paper, we disentangle public spending components in order analyse their effects on the U.S. economy. Our Dynamic Stochastic General Equilibrium Model (DSGE) model includes both civilian and military expenditures. We take into account the changes in the effects of these public spending components before and after the structural break that occurred in the U.S. economy around 1980, namely financial liberalisation. Therefore, we estimate our model with Bayesian methods for two sample periods: 1954:3-1979:2 and 1983:1-2008:2. Our results suggest that total government spending has a positive effect on output, but it induces a fall in private consumption. Moreover, we find important differences between the effects of civilian and military spending. In the pre-1980 period, higher civilian spending induced a rise in private consumption, whereas military spending shocks systematically decreased it. Our findings indicate that civilian spending has a more positive impact on output than military expenditure. Our robustness analysis assesses the impact of public spending shocks under alternative monetary policy assumptions.
\end{abstract}

Keywords: military and civilian spending; DSGE model; fiscal policy; monetary policy; Bayesian estimation

JEL Classification: C11; E21; E62; E63

\section{Introduction}

The effect of an increase in government spending is a central issue in macroeconomics. In this regard, different macroeconomic models have achieved contrasting conclusions about the response of private consumption to government spending shocks (see, among others: Baxter and King 1993; Ambler and Paquet 1996; Linnemann and Schabert 2006; Forni et al. 2009; Leeper et al. 2010; Enders et al. 2011; Coenen et al. 2012; Corsetti et al. 2012; Kormilitsina and Zubairy 2018; Beidas-Strom and Lorusso 2019).

It is also well known that around the early 1980s, the transmission of fiscal policy shocks actually changed (see, for example: Fatás and Mihov 2001; Blanchard and Perotti 2002; Perotti 2005; Galí et al. 2007). Such a change is related to the increased asset market participation by households (Bilbiie et al. 2008). During the 1960s and the 1970s, a large fraction of households was prevented access to financial markets due to significant restrictions. Starting from the early 1980s, financial liberalisation widened private access to financial markets. In turn, such a change had an important influence on the private consumption response to government spending shocks.

In this paper, we develop and estimate a Dynamic Stochastic General Equilibrium (DSGE) model, which includes two different components of government spending, namely civilian and military 
expenditures. In line with the so-called "military Keynesianism" (see Pieroni et al. 2008), we assume that spending decisions for these two different government components are independent. According to the proponents of this view, defence expenditure satisfies two particular conditions: Firstly, it is financed independently of the other public spending categories (such as education and health). Secondly, decisions about the defence sector are taken from institutions that are independent of the other government sectors (the Department of Defence in the U.S.).

Our DSGE model tries to explain the possible sources of crowding in/out effects in consumption observed in the data. To do so, we take into consideration heterogeneous households as in Galí et al. (2007) and Lorusso and Pieroni (2017). A share of households does not have access to the bond market and consumes their current disposable income at each date. On the other hand, a share of households has access to financial markets, smoothing their consumption in the desired way. Firms that produce differentiated goods decide on labour input and set prices according to the model of Calvo (1983). The fiscal policy authority purchases consumption goods, which are divided into spending for the military and non-military sectors, and raises lump-sum taxes and income taxes and issues nominal debt. Finally, our model encompasses a central bank, which sets its policy instrument, the nominal interest rate, by the rule of Taylor (1993).

We estimate our model with Bayesian techniques using U.S. data for two sub-samples: 1954:3-1979:2 (S1) and 1983:1-2008:2 (S2). This sample split allows us to analyse the changes in fiscal shocks before and after the potentially important changes to the financial markets mentioned above.

The main contribution of this paper with respect to previous literature is twofold. Firstly, we include the disaggregated components of civilian and military spending in a DSGE theoretical framework. This allows us to assess the effects of these two public spending components on several macroeconomic aggregates and, in particular, on private consumption. Secondly, we use the Bayesian approach to estimate the effects of fiscal policy shocks on the economy. This allows us to avoid the well-known shortcomings in the identification of military shocks that are associated with the neoclassical literature (Ramey and Shapiro 1999; Ramey 2011) based on the so-called "narrative approach". 1

Our estimated results show that, in the U.S., the share of asset holders increased after the financial liberalisation that occurred in the early 1980s. Such an increase has important consequences on the effects of public spending shocks on the economy. In particular, we find that total government, non-military and military spending shocks affect the U.S. economy differently. An increase in total government expenditure has a positive effect on output, but it induces a fall in private consumption (the so-called crowding-out effect). This occurs because the negative wealth effect generated by the increase in taxation leads both non-asset and asset-holders to increase their labour supply. Accordingly, the fall in the aggregate wage lowers households' disposable income, and in turn, private consumption decreases.

On the other hand, an increase in non-military spending induced a crowding-in effect on consumption in the pre-1980s period. Such an outcome occurred because the lower persistence of the non-military spending shock implies a lower wealth effect on asset holders, and subsequently, the shift in labour demand dominates the shift in labour supply. Accordingly, the real wage increases enough to raise aggregate consumption. Our results also indicate that military spending shocks have a less positive effect on output than civilian spending shocks in both sub-samples.

Finally, we analyse the role of monetary policy in the presence of several public spending shocks. We find that a higher nominal interest rate associated with a more aggressive monetary policy tends to strengthen household incentives to postpone consumption, inducing a negative effect on output.

The rest of the paper is structured as follows. The model is presented in Section 2. In Section 3, we describe the data used for our analysis, discuss the parameters of the model, and report the estimated

1 For a detailed discussion about the criticism of the narrative approach, refer to Perotti (2005). 
results. Section 4 presents the impulse response analysis of our estimated models, and Section 5 provides the robustness analysis. Finally, Section 6 concludes.

\section{The Model}

In this section, we present our DSGE model, which is in line with the theoretical framework developed by Bilbiie et al. (2008). ${ }^{2}$

\subsection{Households}

We assume a continuum of infinitely-lived households $[0,1]$ that are divided in two fractions: asset holders and non-asset holders. Asset holders are denoted with the fraction $1-\lambda$. They trade a risk-less one period bond and hold shares in firms. The non-asset holders are denoted by $\lambda$. They do not participate in asset markets and simply consume their disposable income.

\subsubsection{Asset Holders}

These households face the following intertemporal problem:

$$
\max _{\left\{C_{A, t}, L_{A, t}, B_{A, t+1}\right\}} E_{t} \sum_{t=o}^{\infty} \beta^{t} \frac{\left(C_{A, t} L_{A, t}^{\varphi}\right)^{1-\sigma}}{1-\sigma}
$$

where $\beta \in(0,1)$ denotes the discount factor, $\varphi$ indicates the inverse of the Frish elasticity and $\sigma$ is the inverse of the intertemporal elasticity of substitution. Moreover, $C_{A, t}, L_{A, t}$ and $B_{A, t+1}$ denote, respectively, consumption, leisure and nominal bond holdings for each asset holder.

The asset holder intertemporal budget constraint is expressed by:

$$
R_{t}^{-1} B_{A, t+1}+P_{t} C_{A, t}+P_{t} T_{t}=B_{A, t}+(1-\tau)\left(W_{t} N_{A, t}+P_{t} D_{A, t}\right)
$$

where $\tau$ is the income tax rate that is assumed to be constant and $\left(T_{t}\right)$ denotes the real lump-sum taxes that are adjusted to a rule specified below. Moreover, we indicate by $R_{t}$ the gross nominal return on bonds purchased in period $t$, whereas $P_{t}$ is the price level, $W_{t}$ the nominal wage and $D_{A, t}$ the real dividend payments to households who own shares in the monopolistically-competitive firms. Finally, $N_{A, t}$ indicates the hours worked by the asset holder. If we assume that time endowment is normalized to one, then we have: $N_{A, t}=1-L_{A, t}$.

\subsubsection{Non-Asset Holders}

In each period $t$, these households solve the following intratemporal problem:

$$
\max _{\left\{C_{N, t}, L_{N, t}\right\}} \frac{\left(C_{N, t} L_{N, t}^{\varphi}\right)^{1-\sigma}}{1-\sigma}
$$

subject to the following budget constraint:

$$
P_{t} C_{N, t}=(1-\tau) W_{t} N_{N, t}-P_{t} T_{t}
$$

where $C_{N, t}$ and $N_{N, t}$ denote consumption and hours worked by non-asset holders, respectively. Equation (4) implies that non-asset holder consumption equals their net income.

2 Appendices A-C report the full derivation of the model. 


\subsection{Firms}

Firms in the final goods market are competitive. They use the following aggregation technology:

$$
Y_{t}=\left(\int_{0}^{1} Y_{t}(i)^{\frac{\varepsilon-1}{\varepsilon}} d i\right)^{\frac{\varepsilon}{\varepsilon-1}}
$$

where $Y_{t}(i)$ denotes the quantity of intermediate goods $i \in[0,1]$, at time $t$, used as input. Moreover, $\varepsilon$ is the constant elasticity of substitution.

Firms in the final goods market have the following profit maximization problem:

$$
\max _{\left\{Y_{t}(i)\right\}} P_{t} Y_{t}-\int_{0}^{1} P_{t}(i) Y_{t}(i) d i
$$

where $P_{t}$ is the price index for the final goods and $P_{t}(i)$ denotes the price of the intermediate goods $i$. From the first order condition for $Y_{t}(i)$, we obtain the downward sloping demand for each intermediate input:

$$
Y_{t}(i)=\left(\frac{P_{t}(i)}{P_{t}}\right)^{-\varepsilon} Y_{t}
$$

This implies a price index equal to:

$$
P_{t}=\left[\int_{0}^{1}\left(P_{t}(i)\right)^{1-\varepsilon} d i\right]^{\frac{1}{1-\varepsilon}}
$$

The intermediate goods, $Y_{t}(i)$, are produced by monopolistically-competitive producers that face a production function that is linear in labour and subject to a fixed cost $F$ :

$$
Y_{t}(i)=N_{t}(i)-F, \text { if } N_{t}(i)>F, \text { otherwise, } Y_{t}(i)=0
$$

Thus, real profits for these firms correspond to:

$$
O_{t}(i) \equiv\left[\frac{P_{t}(i)}{P_{t}}\right] Y_{t}(i)-\left[\frac{W_{t}}{P_{t}}\right] N_{t}(i)
$$

We assume that intermediate goods firms face Calvo-style price-setting frictions (Calvo 1983). This implies that intermediate firms can reoptimize their prices with probability $(1-\alpha)$, whereas with probability $\alpha$, they keep their prices constant as in a given period. A firm $i$, resetting its price in period $t$, solves the following maximization problem:

$$
\max _{\left\{P_{t}^{*}(i)\right\}} E_{t} \sum_{s=0}^{\infty} \alpha^{s} \Lambda_{t, t+s}\left[P_{t}^{*}(i) Y_{t, t+s}(i)-W_{t+s} Y_{t, t+s}(i)\right]
$$

subject to the demand function:

$$
Y_{t+s}(i)=\left(\frac{P_{t}^{*}(i)}{P_{t+s}}\right)^{-\varepsilon} Y_{t+s}
$$

where $P_{t}^{*}(i)$ is the optimal price chosen by firms resetting prices at time $t$. Finally, the expression for the price law of motion is equal to:

$$
P_{t}=\left[\alpha\left(P_{t-1}\right)^{1-\epsilon}+(1-\alpha)\left(P_{t}^{*}\right)^{1-\epsilon}\right]^{\frac{1}{1-\epsilon}}
$$




\subsection{Fiscal Policy}

The government budget constraint is given by:

$$
R_{t}^{-1} B_{t+1}=B_{t}+P_{t}\left[G_{t}-\tau Y_{t}-T_{t}\right]
$$

where $(\tau)$ and $\left(T_{t}\right)$ denote distortionary and lump-sum taxes, respectively. Moreover, $\left(B_{t}\right)$ indicates the one-period nominal discount bonds.

We analyse two different cases: firstly, we focus on the model with total government spending; secondly, we disentangle public expenditure into civilian and military components.

\subsubsection{Total Government Spending}

In the model with aggregated public expenditure, total government spending is treated as an exogenous $A R(1)$ process:

$$
\begin{aligned}
& \log \left(G_{t}\right)=\rho^{G} \log \left(G_{t-1}\right)+\epsilon_{t}^{G} \\
& \text { where: } \epsilon_{t}^{G} \sim N\left(0, \sigma_{G}^{2}\right)
\end{aligned}
$$

where $\rho^{G}$ indicates the persistence of total government spending and $\epsilon_{t}^{G}$ is an i.i.d. distributed error term that captures the shock volatility.

\subsubsection{Non-Military and Military Expenditures}

In the model with disaggregated components of public expenditure, we adopt the additive principle where total government spending can be seen as the sum of its different components. Thus, government spending is divided into civilian sector spending $\left(N M_{t}\right)$ and military sector spending $\left(M_{t}\right)$ :

$$
G_{t}=N M_{t}+M_{t}
$$

We assume that civilian and military expenditure levels are independent and exogenous $A R(1)$ processes:

$$
\begin{gathered}
\log \left(N M_{t}\right)=\rho^{N M} \log \left(N M_{t-1}\right)+\epsilon_{t}^{N M}, \\
\text { where: } \epsilon_{t}^{N M} \sim N\left(0, \sigma_{N M}^{2}\right) \\
\log \left(M_{t}\right)=\rho^{M} \log \left(M_{t-1}\right)+\epsilon_{t}^{M}, \\
\text { where: } \epsilon_{t}^{M} \sim N\left(0, \sigma_{M}^{2}\right)
\end{gathered}
$$

where $\rho^{N M}$ and $\rho^{M}$ are, respectively, the persistence parameters of the civilian and military shocks, while $\epsilon_{t}^{N M}$ and $\epsilon_{t}^{M}$ are, respectively, the stochastic civilian and military terms that are i.i.d. distributed.

\subsubsection{Financing Mechanism of Public Expenditure}

The government primary deficit is defined as:

$$
D_{t}=G_{t}-\tau Y_{t}-T_{t}
$$

Equation (18) simply means that government primary deficit is the total non-interest spending less revenues. Moreover, we assume that the government incurs a structural deficit $\left(D_{s, t}\right)$, which is given by the changes in the primary deficit adjusted by automatic responses of tax revenues resulting from deviations on output from its steady state value $(Y)$ :

$$
D_{s, t}=D_{t}+\tau\left(Y_{t}-Y\right)=G_{t}-T_{t}-\tau Y
$$


We assume that the structural deficit is adjusted according to the following log-linearized rule:

$$
d_{s, t}=\eta d_{s, t-1}+\phi_{g} G_{Y} g_{t}
$$

This type of rule is in line with those used by Bohn (1998) and Galí and Perotti (2003). The parameter $\eta$ captures the possibility that budget decisions are autocorrelated. The parameters $\phi_{g}$ measure the response of structural deficit to changes in government spending.

\subsection{Monetary Policy}

We assume that the monetary authority sets the nominal interest according to the following log-linearized monetary policy reaction function:

$$
r_{t}=\rho^{R} r_{t-1}+\left(1-\rho^{R}\right)\left\{\bar{\pi}_{t}+r_{\pi}\left(\pi_{t-1}-\bar{\pi}_{t}\right)+r_{y}\left(y_{t}-y\right)\right\}+\epsilon_{t}^{R}
$$

where $\rho_{R}$ is an interest rate smoothing parameter, whereas $\pi_{t}$ denotes the inflation rate. Equation (21) implies that the central bank responds to deviations of lagged inflation from an inflation objective and to an output gap defined as the difference between actual and steady state output (Rabanal and Rubio-Ramírez 2001).

Our monetary policy rule assumes two exogenous shocks: The first is a shock to the inflation objective $\left(\bar{\pi}_{t}\right)$, which is assumed to follow a first order autoregressive process:

$$
\begin{aligned}
& \log \left(\bar{\pi}_{t}\right)=\rho^{\bar{\pi}} \log \left(\bar{\pi}_{t-1}\right)+\epsilon_{t}^{\bar{\pi}} \\
& \text { where: } \epsilon_{t}^{\bar{\pi}} \sim N\left(0, \sigma_{\bar{\pi}}^{2}\right)
\end{aligned}
$$

The second shock is a temporary i.i.d. monetary policy shock $\epsilon_{t}^{R} \sim N\left(0, \sigma_{R}^{2}\right)$.

\subsection{General Equilibrium and Aggregation}

The final goods market clearing condition is given by:

$$
Y_{t}=C_{t}+G_{t}
$$

that is production equals demand by total household consumption and total government spending. The aggregate consumption is given by:

$$
C_{t}=\lambda C_{N, t}+(1-\lambda) C_{A, t}
$$

The equilibrium in the labour market is given by:

$$
N_{t}=\lambda N_{N, t}+(1-\lambda) N_{A, t}
$$

that is the wage level is such that demand by firms for labour equals total labour supply. Finally, the equilibrium in the share market is given by:

$$
B_{t+1}=(1-\lambda) B_{A, t+1}
$$

that is households hold all outstanding equity shares and all government debt is held by asset holders.

\section{Estimating the Model}

In this section, we focus on the estimated results of our model. We start by describing the data, then we discuss the assumptions on the prior distributions of the parameters estimated with Bayesian techniques. Finally, we present the posterior estimates of such parameters. 


\subsection{Data Description}

Our model is estimated on U.S. data for two samples, 1954:3-1979:2 (S1) and 1983:1-2008:2 (S2). As we explained above, in the early 1980s, financial liberalisation occurred. Therefore, our choice of splitting the overall sample reflects the hypothesis of a structural break in such a period.

Our choice of ending S2 in 2008:2 is because this period coincides with the beginning of the U.S. financial crisis. As a consequence, the Fed adopted an unconventional monetary policy, which resulted in the short-term nominal interest rate approaching the zero-lower bound. As Christiano et al. (2011) and Ramey and Zubairy (2018) argued, in such a situation, the effects of fiscal spending shocks on several macroeconomic aggregates substantially changed with respect to "normal" times.

As we mentioned above, we have two separate models. In the first model, we assumed that the whole economy was driven by three exogenous shocks: total government spending $\left(\epsilon_{t}^{G}\right)$, inflation objective $\left(\epsilon_{t}^{\bar{\pi}}\right)$ and monetary policy $\left(\epsilon_{t}^{R}\right)$. Since there were three exogenous shocks, we used three observed variables to estimate this model: total government spending, inflation rate and short-term nominal interest rate. The series of the total government spending was taken from the U.S. Bureau of Economic Analysis (BEA). The inflation rate corresponded to the quarterly growth rate of the GDP price index. For the short-term nominal interest rate, we considered the effective federal funds rate expressed in quarterly terms. The source of these two data series was the website of the Federal Reserve Bank of St. Louis.

In the second model, we disaggregated total public spending into non-military and military components. Thus, the exogenous processes governing the economy were four: non-military expenditure $\left(\epsilon_{t}^{N M}\right)$, military spending $\left(\epsilon_{t}^{M}\right)$, inflation objective $\left(\epsilon_{t}^{\bar{\pi}}\right)$ and monetary policy $\left(\epsilon_{t}^{R}\right)$. Thus, we used four observed variables to estimate this model: non-military expenditure, military expenditure, inflation rate and short-term nominal interest rate. The data series for non-military and military spending were obtained from the U.S. BEA. In particular, military spending corresponded to national defence data, whereas non-military spending was obtained from the difference between government consumption expenditures and gross investment data and national defence data. For inflation rate and short-term nominal interest rate, we used the data series that we mentioned above.

In both models, we deflated all variables using their respective deflators. Moreover, we expressed the several variables in log per capita terms. Finally, we detrended all the series using the Hodrick-Prescott filter with a smoothing parameter equal to 1600 .

\subsection{Prior Distributions of the Parameters}

We split the parameters of our models into two groups. The first set was kept fixed. The parameters of this group can be viewed as strict priors, and we set their values in line with previous literature (Galí et al. 2007; Bilbiie et al. 2008). The second group of parameters was estimated using the Bayesian method.

Table 1 shows the fixed parameters in the two sub-samples for both the aggregate government spending model and the disaggregated model. From Panel (a), we note that the share of government expenditure on GDP in S1 was higher than the one in S2. This reflects that fact that the average of public spending decreased over time. Focusing on the disaggregated model, Panel (b) shows that also the shares of non-military spending on GDP $\left(N M_{Y}\right)$ and military spending on GDP $\left(M_{Y}\right)$ decreased from S1 to S2. 
Table 1. Fixed parameters for both models. S, Sub-sample.

\begin{tabular}{ccc}
\hline Parameter & S1 (1954:Q3-1979:Q2) & S2 (1983:Q1-2008:Q2) \\
\hline & (a) Model with Total Government Spending \\
\hline$\beta$ & 0.99 & 0.99 \\
$G_{Y}$ & 0.28 & 0.18 \\
$\tau$ & 0.30 & 0.30 \\
$\phi_{g}$ & 0.17 & 0.64 \\
$\eta$ & 0.51 & 0.71 \\
$\alpha$ & 0.75 & 0.75 \\
$\sigma$ & 2.00 & 2.00 \\
$N$ & 0.25 & 0.25 \\
\hline$(b)$ Model with Non-Military and Military Expenditures \\
\hline$\beta$ & 0.99 & 0.99 \\
$G_{Y}$ & 0.28 & 0.18 \\
$M_{Y}$ & 0.10 & 0.06 \\
$N M_{Y}$ & 0.18 & 0.12 \\
$\phi_{g}$ & 0.17 & 0.64 \\
$\eta$ & 0.51 & 0.71 \\
$\tau$ & 0.30 & 0.30 \\
$\alpha$ & 0.75 & 0.75 \\
$\sigma$ & 2.00 & 2.00 \\
$N$ & 0.25 & 0.25 \\
\hline
\end{tabular}

In line with Bilbiie et al. (2008), we kept $\phi_{g}$ equal to 0.17 in S1 and 0.64 in S2 for both the aggregate government spending model and the disaggregated expenditure model. This implies that there was a greater reliance on deficits to finance an extra public spending unit in S2 than S1. Following Bilbiie et al. (2008), we fixed $\eta$ equal to 0.51 in the first sub-sample and to 0.71 in the second sub-sample for both the aggregate government expenditure model and the disaggregated spending model. Such values imply a greater persistence of deficits in the second sub-sample.

For the remaining fixed parameters, we used the same values for both sub-samples and in both models. The discount factor $(\beta)$ corresponded to 0.99 , which implies an annual steady state real interest rate of $4 \%$. Moreover, we assumed that, in the steady state, agents spend one-fourth of their time endowment working. Following Bilbiie et al. (2008), we set the inverse of the intertemporal elasticity of substitution $(\sigma)$ equal to two. The price elasticity of demand for intermediate goods $(\varepsilon)$ was chosen such that the mark-up in the steady state equalled 20\%. Moreover, in line with Del Negro and Schorfheide (2008), we fixed the probability that prices did not change in a given period $(\alpha)$ at 0.75 . Finally, we set the steady state tax rate $(\tau)$ equal to 0.3 . Together with the assumption that the steady-state share of debt was zero, these last two parameters pinned down lump-sum transfers in the steady state.

Table 2 displays the prior distributions of the endogenous parameters estimated with Bayesian techniques for both models in S1 and S2. We start by describing our prior assumptions on the share of non-asset holders. In line with the findings by Bilbiie et al. (2008), for both models, we assumed that $(\lambda)$ was gamma distributed and had a higher prior mean in S1 than S2. 
Table 2. Priors of endogenous parameters for both models.

\begin{tabular}{|c|c|c|c|c|c|}
\hline Parameter & Prior Distribution & \multicolumn{2}{|c|}{ Prior Mean } & \multicolumn{2}{|c|}{ Prior St. Dev. } \\
\hline \multicolumn{6}{|c|}{ (a) Model with Total Government Spending } \\
\hline & & S1 & $S 2$ & S1 & $S 2$ \\
\hline$\rho^{R}$ & Beta & 0.65 & 0.65 & 0.10 & 0.10 \\
\hline$r_{\pi}$ & Gamma & 1.50 & 1.50 & 0.10 & 0.10 \\
\hline$r_{y}$ & Gamma & 0.10 & 0.10 & 0.05 & 0.05 \\
\hline$\lambda$ & Gamma & 0.50 & 0.30 & 0.01 & 0.01 \\
\hline \multicolumn{6}{|c|}{ (b) Model with Non-Military and Military Expenditure } \\
\hline & & S1 & $S 2$ & S1 & $S 2$ \\
\hline$\rho^{R}$ & Beta & 0.65 & 0.65 & 0.10 & 0.10 \\
\hline$r_{\pi}$ & Gamma & 1.50 & 1.50 & 0.10 & 0.10 \\
\hline$r_{y}$ & Gamma & 0.10 & 0.10 & 0.05 & 0.05 \\
\hline$\lambda$ & Gamma & 0.50 & 0.30 & 0.01 & 0.01 \\
\hline
\end{tabular}

Notes: In the above table, S1 denotes the first sub-sample, whereas S2 indicates the second sub-sample.

Turning to the parameters of the monetary policy rule, we chose a pretty general and agnostic approach by assuming the same prior distributions in both sub-samples and for both models. Our priors were in line with the values found by Smets and Wouters (2007). In particular, we assumed that the interest rate smoothing parameter was beta distributed with prior mean and standard deviation corresponding to 0.65 and 0.10 , respectively. The prior for the coefficient on inflation was assumed to have a gamma distribution with mean equal to 1.5 and standard deviation equal to 0.1 . Moreover, we assumed that the coefficient on output was gamma distributed with mean equal to 0.10 and standard deviation equal to 0.05 .

Table 3 shows the priors of the stochastic processes. The distribution for these parameters was the same in both models and sub-samples. In line with Smets and Wouters (2007), we assumed that the persistence parameters of the $A R(1)$ processes were beta distributed with means equal to 0.70 and standard deviations equal to 0.20 . Finally, the standard errors of the innovations were assumed to follow inverse-gamma distributions with mean equal to 0.01 and infinite degrees of freedom.

Table 3. Priors of shock processes for both models.

\begin{tabular}{|c|c|c|c|c|c|}
\hline Parameter & Prior Distribution & \multicolumn{2}{|c|}{ Prior Mean } & \multicolumn{2}{|c|}{ Prior St. Dev. } \\
\hline \multicolumn{6}{|c|}{ (a) Model with Total Government Spending } \\
\hline & & S1 & $S 2$ & S1 & $S 2$ \\
\hline$\rho^{G}$ & Beta & 0.70 & 0.70 & 0.20 & 0.20 \\
\hline$\rho^{\pi}$ & Beta & 0.70 & 0.70 & 0.20 & 0.20 \\
\hline$\sigma_{G}$ & Inverse-Gamma & 0.01 & 0.01 & $\operatorname{Inf}$. & $\operatorname{Inf}$. \\
\hline$\sigma_{\pi}$ & Inverse-Gamma & 0.01 & 0.01 & Inf. & Inf. \\
\hline$\sigma_{R}$ & Inverse-Gamma & 0.01 & 0.01 & $\operatorname{Inf}$. & $\operatorname{Inf}$. \\
\hline \multicolumn{6}{|c|}{ (b) Model with Non-Military and Military Expenditure } \\
\hline & & S1 & $S 2$ & S1 & $S 2$ \\
\hline$\rho^{N M}$ & Beta & 0.70 & 0.70 & 0.20 & 0.20 \\
\hline$\rho^{M}$ & Beta & 0.70 & 0.70 & 0.20 & 0.20 \\
\hline$\rho^{\pi}$ & Beta & 0.70 & 0.70 & 0.20 & 0.20 \\
\hline$\sigma_{N M}$ & Inverse-Gamma & 0.01 & 0.01 & $\operatorname{Inf}$. & $\operatorname{Inf}$. \\
\hline$\sigma_{M}$ & Inverse-Gamma & 0.01 & 0.01 & $\operatorname{Inf}$. & $\operatorname{Inf}$. \\
\hline$\sigma_{\pi}$ & Inverse-Gamma & 0.01 & 0.01 & Inf. & Inf. \\
\hline$\sigma_{R}$ & Inverse-Gamma & 0.01 & 0.01 & $\operatorname{Inf}$. & $\operatorname{Inf}$. \\
\hline
\end{tabular}

Notes: In the above table, S1 denotes the first sub-sample, whereas S2 indicates the second sub-sample. 


\subsection{Posterior Estimates of the Parameters}

In both models and in both sub-samples, for the group of parameters estimated with the Bayesian method, firstly, we estimated the mode of the posterior distribution by maximising the log posterior function, which combined the priors with the likelihood function given by the data. Secondly, we used the Metropolis-Hastings algorithm to obtain the full posterior distribution. ${ }^{3}$ Our samples included $1,000,000$ draws, and we dropped the first 250,000 of them. The acceptancerates for the total government spending model corresponded to 35\% in S1 and 33\% in S2, whereas for the model with disaggregated public spending, the components in S1 and S2 were equal to 32\% and 33\%, respectively. In order to test the stability of the samples, we used the diagnostic test of Brooks and Gelman (1998). We also used other diagnostic tests for our estimates, including the Monte Carlo Markov Chain (MCMC) univariate diagnostics and the multivariate convergence diagnostics. In terms of parameters identification, we performed the test of Iskrev (2010). ${ }^{4}$ Such a test shows that all the parameters for both models and in both sub-samples were identifiable in the neighbourhood of our estimates. Finally, we tested for the possibility of the misspecification of our DSGE model. In line with Albonico et al. (2019), we estimated the DSGE-VAR counterparts (in the spirit of Del Negro and Schorfheide 2004) for the models with aggregate government spending, as well as disaggregated non-military and military expenditures in both sub-samples. Overall, our results indicated that, in both sub-samples, the benchmark models outperformed the different DSGE-VAR models. ${ }^{5}$

Tables 4 and 5 report the posterior means for the parameters of both models for S1 and S2 with a $90 \%$ confidence interval.

Table 4. Estimated posteriors of endogenous parameters for both models.

\begin{tabular}{ccccccc}
\hline Parameter & Posterior Mean & Confidence Interval & Posterior Mean & Confidence Interval \\
\hline \multicolumn{7}{c}{ S1 (1954:Q3-1979:Q2) } \\
\hline \multicolumn{7}{c}{ (a) Model with Total Government Spending } \\
\hline$\rho^{R}$ & 0.3240 & 0.2576 & 0.3894 & 0.3961 & 0.3362 & 0.4557 \\
$r_{\pi}$ & 1.5330 & 1.3677 & 1.6937 & 1.4920 & 1.3314 & 1.6513 \\
$r_{y}$ & 0.1396 & 0.0363 & 0.2355 & 0.1286 & 0.0340 & 0.2237 \\
$\lambda$ & 0.4484 & 0.4390 & 0.4559 & 0.2898 & 0.2743 & 0.3051 \\
\hline \multicolumn{7}{c}{ Podel with Non-Military and Military Expenditures } \\
\hline$\rho^{R}$ & 0.2419 & 0.1647 & 0.3208 & 0.3664 & 0.2969 & 0.4362 \\
$r_{\pi}$ & 1.5194 & 1.3634 & 1.6816 & 1.4835 & 1.3201 & 1.6416 \\
$r_{y}$ & 0.1183 & 0.0290 & 0.2009 & 0.1252 & 0.0300 & 0.2142 \\
$\lambda$ & 0.4488 & 0.2998 & 0.5384 & 0.2901 & 0.2745 & 0.3053 \\
\hline
\end{tabular}

3 All the estimations were done with Dynare (http:/ / www.dynare.org/).

4 All the relative figures are reported in Appendix D together with prior and posterior distributions of the parameters estimated with Bayesian methods.

5 In Appendix F, Tables A1 and A2 compare the different DSGE-VAR models against the benchmark models, reporting their marginal log densities and Bayes factors. 
Table 5. Estimated posteriors of shock processes for both models.

\begin{tabular}{ccccccc}
\hline Parameter & Posterior Mean & \multicolumn{2}{c}{ Confidence Interval } & Posterior Mean & \multicolumn{2}{c}{ Confidence Interval } \\
\hline \multicolumn{7}{c}{ S1 (1954:Q3-1979:Q2) } \\
\hline \multicolumn{7}{c}{ (a) Model with Total Government Spending } \\
\hline$\rho^{G}$ & 0.8231 & 0.7340 & 0.9116 & 0.7628 & 0.6653 & 0.8607 \\
$\rho^{\pi}$ & 0.9629 & 0.9305 & 0.9980 & 0.9580 & 0.9223 & 0.9966 \\
$\sigma_{G}$ & 0.4954 & 0.4390 & 0.5520 & 0.3155 & 0.2819 & 0.3492 \\
$\sigma_{\pi}$ & 0.2270 & 0.1624 & 0.2927 & 0.2921 & 0.1976 & 0.3900 \\
$\sigma_{R}$ & 1.3924 & 1.1659 & 1.6141 & 1.2582 & 1.0998 & 1.4162 \\
\hline \multicolumn{7}{c}{ Podel with Non-Military and Military Expenditures } \\
\hline$\rho^{N M}$ & 0.6152 & 0.4861 & 0.7413 & 0.8049 & 0.7192 & 0.8934 \\
$\rho^{M}$ & 0.9291 & 0.8830 & 0.9785 & 0.8394 & 0.7552 & 0.9236 \\
$\rho^{\pi}$ & 0.9601 & 0.9264 & 0.9975 & 0.9564 & 0.9196 & 0.9962 \\
$\sigma_{N M}$ & 0.5104 & 0.4501 & 0.5688 & 0.3273 & 0.2919 & 0.3624 \\
$\sigma_{M}$ & 0.9652 & 0.8502 & 1.0741 & 0.8604 & 0.7671 & 0.9534 \\
$\sigma_{\pi}$ & 0.2101 & 0.1482 & 0.2689 & 0.2894 & 0.1936 & 0.3869 \\
$\sigma_{R}$ & 1.4603 & 1.2293 & 1.6907 & 1.2815 & 1.1146 & 1.4454 \\
\hline
\end{tabular}

We start by describing the estimates of the share of non-asset holders $(\lambda)$. From Table 4, we observe that asset market participation differed considerably across periods. More specifically, for the model with aggregate government spending, the share of consumers who did not smooth consumption by trading in assets was estimated as 0.45 in S1 and as 0.29 in S2. Similar values were found for the model with disaggregated public spending components. These results imply that access to asset markets widened with the important institutional changes in the early 1980s. As we will discuss below, this result had important implications for the several fiscal policy shocks.

Focusing on the estimated parameters for monetary policy, we note that for the model with aggregate government spending in both sub-samples, the nominal interest responded more strongly to inflation than output changes. Our finding was in line with Andrés et al. (2009). Interestingly, we found that the interest smoothing parameter had a larger value in S2 than S1. The estimates for these parameters showed a similar value for the model with disaggregated government spending.

A number of observations are worth making regarding the estimated exogenous processes. In the model with aggregate government spending, we found that the expenditure shock volatility $\left(\sigma_{G}\right)$ was much larger in S1 than S2. Similarly, government spending shocks were more persistent in S1 than S2. Regarding the shocks to monetary policy, the inflation target shock was more volatile in S2 than S1, whereas the nominal interest rate shock had a higher volatility in the first sub-sample. Such results confirm a stronger central bank response to inflation in the second sub-period.

Focusing on the model with non-military and military expenditures, we noted remarkable differences across the two sub-samples and between the two components. Firstly, we noted that the volatilities of the government spending components were larger in the first sub-sample. Secondly, we found that civilian spending shocks were more persistent in S2, whereas the opposite occurred to military expenditure shocks. Thirdly, our results showed that $\sigma_{M}$ was almost double of $\sigma_{N M}$ in both S1 and S2. Such findings confirmed that military spending shocks were much more volatile than civilian shocks. Similarly, military expenditure shocks were more persistent than civilian spending shocks in both sub-samples.

\section{Analysing the Effects of Different Public Spending Shocks on the Economy}

In this section, we show the impulse responses by assuming a $1 \%$ increase in total government, civilian and military expenditures. More specifically, we set the values of the several parameters equal 
to their mean estimates of their posterior distributions. This strategy allowed us to compare the effects of several public spending shocks on the economy effectively. ${ }^{6}$

\subsection{Model with Aggregate Government Spending}

Figure 1 plots the impulse responses to a positive government spending shock. We observed that such a shock was more persistent in the first sub-sample. This result was in line with the studies by Fatás and Mihov (2003) and Perotti (2005).
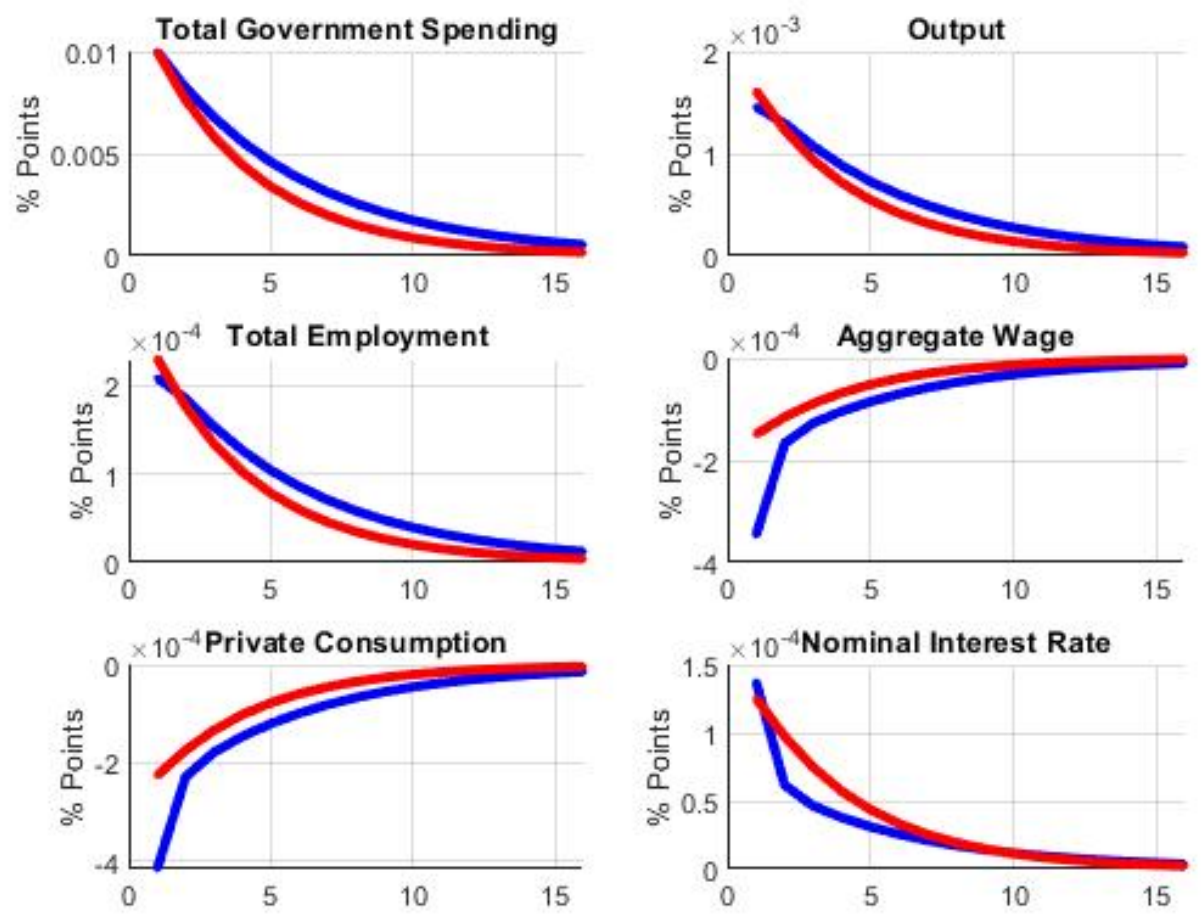

Figure 1. Total government spending shock. Notes: Simulated $1 \%$ increase in total government spending. Parameters are set according to their estimated values. The blue lines indicate the responses of the estimated model for S1, whereas the red lines denote the responses of the estimated model in S2.

Our results indicate that, on the shock impact, output increased by $0.15 \%$ in $\mathrm{S} 1$ and $0.16 \%$ in S2. However, from the fourth quarter onwards, we noted a smaller increase in GDP during the post-financial liberalisation period than in S1. Our findings were in line with Albonico et al. (2017), who found that in recent years, and especially during the Great Recession, the discretionary fiscal stimulus has played a negligible role in stabilising the U.S. economy.

From Figure 1, we note that, in both sub-samples, an increase in government spending induced an increase in hours worked. This occurred because both non-asset and asset holders increased their labour supply due to the negative wealth effect induced by the increase in taxation. Aggregate wages fell in response to the shock because the shift in labour supply dominated the shift in labour demand.

Moreover, the nominal interest rate increased. As a consequence, private consumption decreased. Such a finding confirmed the predictions of standard neoclassical models in which higher government spending tends to depress the consumption of asset holders. The reason was the negative wealth effect resulting from the induced increase in the tax burden. Such an effect was strengthened by the increase

6 In Appendix E, we report the estimated IRFs and their relative error bands for all three public spending shocks in both sub-samples. 
in the nominal interest rate. A more aggressive monetary policy implies a higher real interest rate and, in turn, lowered the incentive of asset holders to postpone consumption.

Interestingly, we found that private consumption had a larger fall in S1 than S2. This is explained by the higher persistence of the government spending shock in the first sub-sample that increased the present discounted value of taxes and the wealth effect on asset holders.

\subsection{Model with Non-Military and Military Expenditures}

Figures 2 and 3 show the impulse responses to non-military and military spending shocks, respectively.

We start by describing the effects of a $1 \%$ increase in non-military spending (Figure 2). We observed that the persistence of the shock was much lower in S1 than S2. Moreover, our results showed that, on impact, output increased by $0.13 \%$ in the first sub-sample and by $0.10 \%$ in the second sub-sample. Similarly, hours worked increased in both S1 and S2.
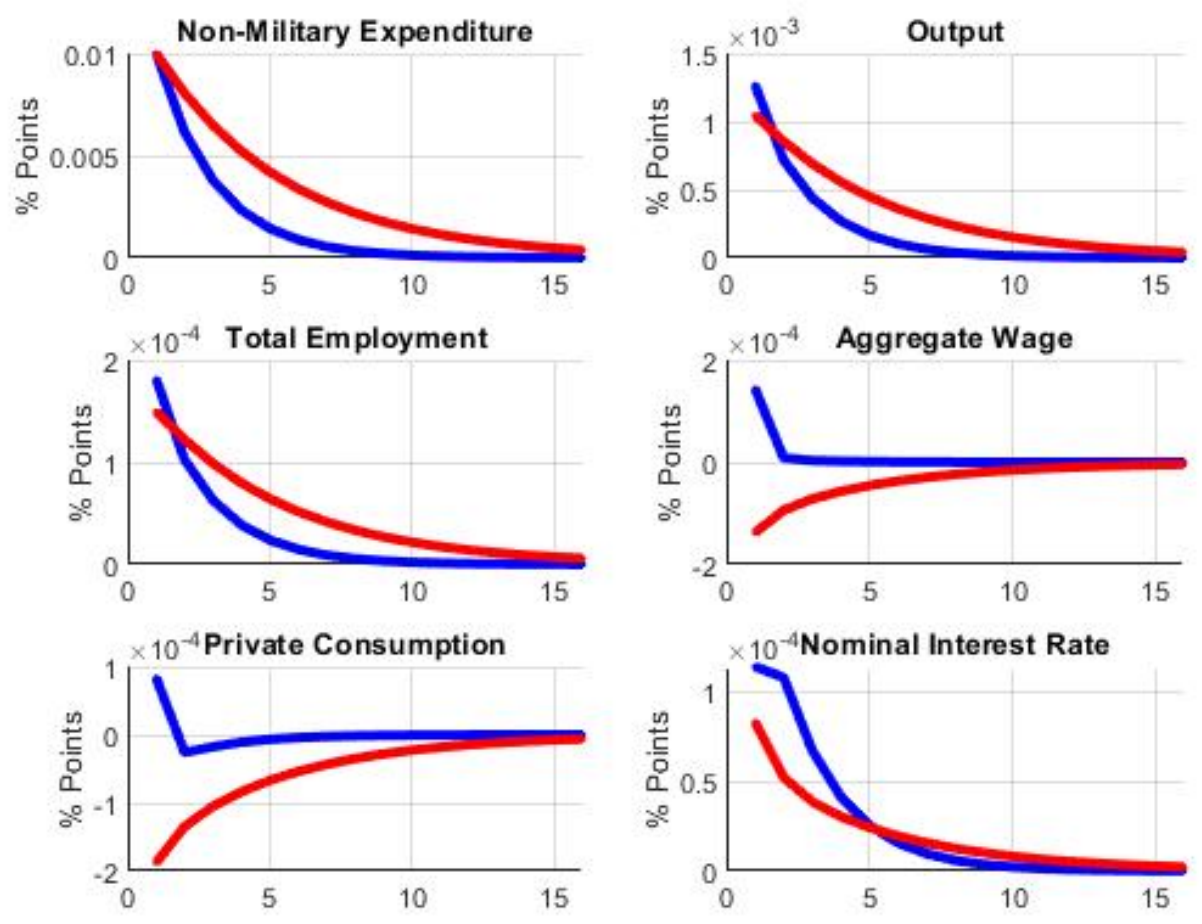

Figure 2. Non-military spending shock. Notes: Simulated 1\% increase in non-military spending. Parameters are set according to their estimated values. The blue lines indicate the responses of the estimated model for S1, whereas the red lines denote the responses of the estimated model in S2.

Interestingly, we noted that the responses of aggregate wage and private consumption were very different across the two sub-samples. In particular, we observed an increase in these two variables in S1, whereas they both fell in S2. Therefore, our results showed the crowding-in effect before the 1980s and the crowding-out effect thereafter. The reason for the crowding-in effect in S1 was the strong enough rise in the real wage. Such an increase induced a rise in the consumption of non-asset holders, which more than offset the fall in consumption of asset holders. The increase in the aggregate wage crucially depended on the interaction between labour demand and supply. On the one hand, a positive civilian spending shock increased the demand for goods and, in turn, affected labour demand. The firms that could not change their prices and had to adjust their quantities hence shifted labour demand at a given wage. On the other hand, labour supply shifted for two different reasons. Firstly, non-asset 
holders would work more as tax burden increased. Secondly, asset holders also increased labour supply for a given wage: this was due both to the wealth effect and to intertemporal substitution.

The lower persistence of the civilian spending shock in S1 implied a lower wealth effect on asset holders, and in turn, the shift in labour demand dominated the shift in labour supply. Accordingly, the real wage increased enough to raise aggregate consumption. Since the opposite effects occurred in the second sub-sample, we observed crowding-out on private consumption. Finally, we note that the nominal interest rate increased more in the first sub-sample, weakening the positive effect of the civilian spending shock on consumption.

We now turn to the effects of a $1 \%$ increase in military spending. As we can observe in Figure 3 , the persistence of this shock was higher in S1 than S2. Interestingly, we note that the positive effect on output implied by these shocks was lower compared to the increased civilian spending for both sub-samples $(0.04 \%$ in S1 and $0.05 \%$ in S2).
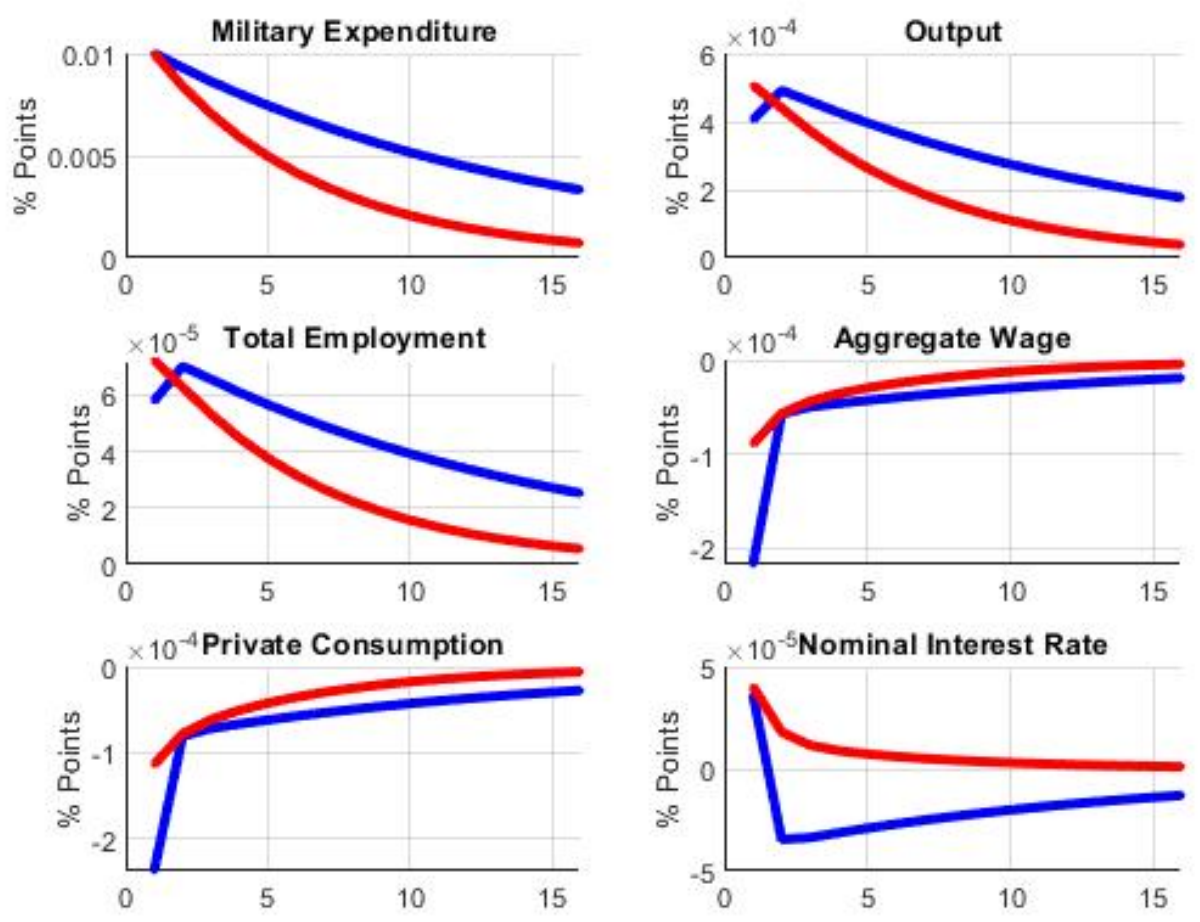

Figure 3. Military spending shock. Notes: Simulated 1\% increase in military spending. Parameters are set according to their estimated values. The blue lines indicate the responses of the estimated model for S1, whereas the red lines denote the responses of the estimated model in S2.

Moreover, it is possible to observe that in both S1 and S2, hours worked increased in response to the shock due to the negative wealth effect associated with the increase in taxation. Our results indicated a larger fall in the aggregate wage during the first sub-sample. As a consequence, private consumption dropped more substantially in S1 than S2.

From these results, it is evident that there were important differences between the effects of civilian and military spending. In the pre- 1980 period, an increase in civilian expenditure induced a crowding-in effect on private consumption for the U.S. economy. On the contrary, military spending 
shocks caused a systematic fall in private consumption. Moreover, we note that the civilian spending had a more positive impact on output than military expenditure for both sub-samples. ${ }^{7}$

\section{Robustness Analysis: Different Assumptions about the Taylor Rule}

In this section, we investigate the role of monetary policy in the presence of the shocks to total government, non-military and military spending. In particular, we provide a counterfactual analysis in which the central bank has a more aggressive monetary policy. More specifically, we assumed that in the Taylor rule (21), the parameters measuring the response of the policy rate to output $\left(r_{y}\right)$ and inflation $\left(r_{\pi}\right)$, as well as the interest rate smoothing parameter $\left(\rho^{R}\right)$ assumed values that were double those estimated by our models.

Figure 4 shows the responses for both output and consumption in the case of an increase in total government, non-military and military spending, respectively. The black lines represent the responses of output and consumption in the presence of the actual monetary policy, whereas the green lines show the IRFs for the same variables in the presence of a more aggressive monetary policy.

As we explained in the previous section, a more aggressive monetary policy implies a higher nominal interest rate that strengthened household incentives to postpone consumption. As a consequence, private consumption and output were lower. In fact, the top panels of Figure 4 show that in the case of total government spending, for the first sub-sample, both output and consumption were lower in the presence of a more aggressive monetary policy (on the shock impact, $0.01 \%$ lower than in the benchmark case). In the second sub-sample, the same effects with similar magnitudes can be observed.

The mid panels of Figure 4 show a more striking difference in the responses of consumption and output to an increase in non-military spending. In S1, although in the presence of the actual monetary policy, private consumption increased, when a more aggressive monetary policy was in operation, the crowding-out effect emerged. In turn, this implies that output in the counterfactual scenario was lower than in the actual case by $0.02 \%$. These effects are less pronounced in the second sub-sample. Finally, the bottom panels of Figure 4 show that different monetary policies had negligible effects in the case of an increase in military spending.

7 In order to further assess the different contribution of fiscal spending shocks on aggregate output, we also performed the forecast error variance decomposition for 1, 4, 10, and 30 quarters ahead (Albonico et al. 2019). Our results indicated that fiscal spending shocks had larger contributions on GDP during the post-financial liberalisation period. Moreover, we found that non-military spending shocks contributed to output changes more than military spending shocks. 
Total Government Spending Shock
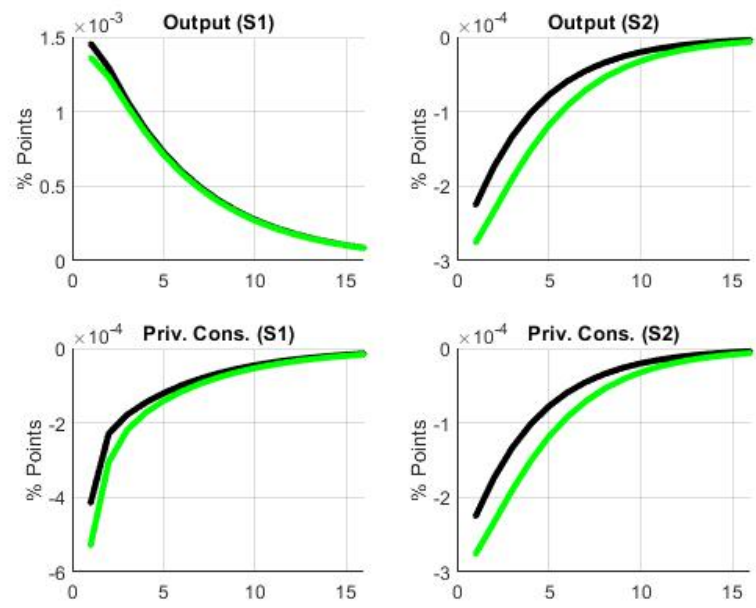

Non-Military Spending Shock
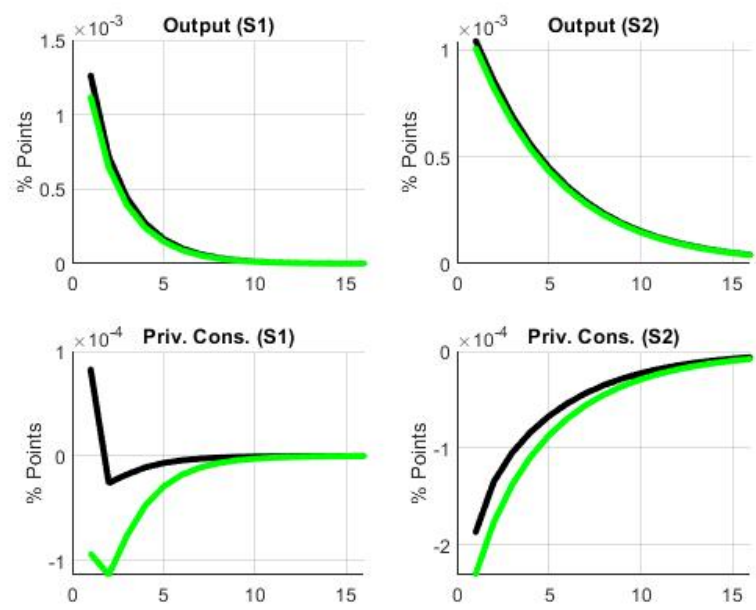

Military Spending Shock
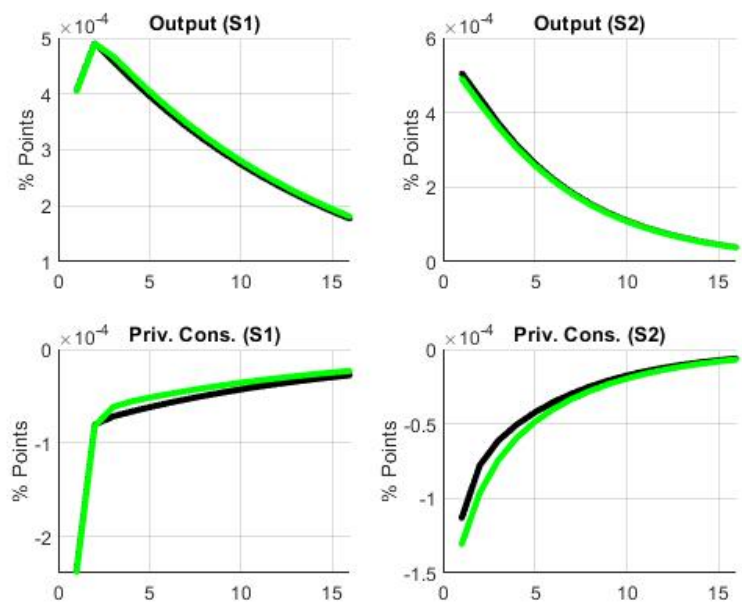

Figure 4. Alternative assumptions on the Taylor rule. Notes: In the above graphs, the black lines denote the IRFsin the presence of the actual U.S. monetary policy, whereas the green lines indicate the IRFs associated with the counterfactual monetary policy. 


\section{Conclusions}

In this paper, the impact of total government, non-military and military spending shocks on the U.S. economy was assessed. We accounted for the established evidence that public spending shocks have changed substantially in the post-1980s. Therefore, we estimated our DSGE model with recent Bayesian techniques for two sample periods: 1954:3-1979:2 and 1983:1-2008:2. Our new Keynesian DSGE model featured limited asset market participation as a potential institutional explanation for different degrees of fiscal policy effectiveness. Therefore, our model allowed us to relate the differences in the transmission of public spending shocks to important financial changes in the U.S. economy.

Our results suggested that asset market participation increased noticeably in the post-1980s, in line with previous evidence in the economic literature. Moreover, we found that an exogenous increase in total government spending led to a higher output, but decreased consumption. Our findings also indicated that, in the first sub-sample, an increase in non-military spending induced a crowding-in effect on consumption. On the contrary, positive shocks to military spending tended to depress private consumption. We also found that military spending shocks had a less positive effect on output than civilian spending shocks in both sub-samples. Finally, we assessed the role of monetary policy in the presence of different public spending shocks. Our findings suggested that a more aggressive monetary policy tended to lower private consumption and output.

Overall, our results indicated that the U.S. economy seemed to benefit from increases in non-military spending. On the other hand, the military Keynesianism hypothesis, which still has many supporters in the U.S., can be at least questionable. The policy implications that can be drawn from our analysis suggested that switching government priorities in favour of supplying civilian goods and services, rather than financing federal defence spending, should foster the U.S. economy.

As future work, it will be intriguing to extend this work by considering a Markov switching rational expectation new-Keynesian model in order to analyse in more detail the change in volatility of fiscal spending shocks in the pre- and post-financial liberalisation periods.

Author Contributions: The work was equally divided between the two co-authors.

Funding: This work was supported by the Department of Political Science, University of Perugia.

Acknowledgments: We thank the editor, the three anonymous referees and Francesco Ravazzolo for their useful comments and suggestions that improved this work.

Conflicts of Interest: The authors declare no conflict of interest.

\section{Appendix A. Maximization Problems of the Model}

From the asset holders utility maximization problem, we obtain the following FOCsfor $C_{A, t}$ and $L_{A, t}$ :

$$
\begin{gathered}
\lambda_{t}=-\frac{L_{A, t}^{\varphi}}{\left(C_{A, t} L_{A, t}^{\varphi}\right)^{\sigma}} \frac{1}{P_{t}} \\
\frac{\varphi C_{A, t} L_{A, t}^{\varphi-1}}{\left(C_{A, t} L_{A, t}^{\varphi}\right)^{\sigma}}=-\lambda_{t}\left[(1-\tau) W_{t}\right]
\end{gathered}
$$

Putting (A1) into (A2), we obtain the labour decision equation:

$$
\frac{C_{A, t}}{L_{A, t}}=\frac{(1-\tau)}{\varphi} \frac{W_{t}}{P_{t}}
$$

The FOC for $B_{A, t+1}$ is:

$$
\lambda_{t} \frac{1}{R_{t}}=\lambda_{t+1} \beta
$$


Putting (A1) into (A5), we obtain the Euler equation:

$$
\frac{1}{R_{t}}=\beta\left(\frac{C_{A, t}}{C_{A, t+1}}\right)^{\sigma}\left(\frac{L_{A, t+1}}{L_{A, t}}\right)^{\varphi(1-\sigma)} \frac{P_{t}}{P_{t+1}}
$$

Thus:

$$
R_{t}^{-1}=\beta E_{t}\left[\Lambda_{t, t+1}\right]
$$

where:

$$
\Lambda_{t, t+s}=\beta^{s}\left(\frac{C_{A, t}}{C_{A, t+s}}\right)^{\sigma}\left(\frac{L_{A, t+s}}{L_{A, s}}\right)^{\varphi(1-\sigma)} \frac{P_{t}}{P_{t+s}}
$$

This is the stochastic discount factor.

From the non-asset holders utility maximization problem, we obtain the following FOCs for $C_{N, t}$ and $L_{N, t}$ :

$$
\begin{gathered}
\lambda_{t}=\frac{L_{N, t}^{\varphi}}{\left(C_{N, t} L_{N, t}^{\varphi}\right)^{\sigma}} \frac{1}{P_{t}} \\
\frac{\varphi C_{N, t} L_{N, t}^{\varphi-1}}{\left(C_{N, t} L_{N, t}^{\varphi}\right)^{\sigma}}=\lambda_{t}\left[(1-\tau) W_{t}\right]
\end{gathered}
$$

Putting (A8) into (A9) gives the labour decision equation:

$$
\frac{C_{N, t}}{L_{N, t}}=\frac{(1-\tau)}{\varphi} \frac{W_{t}}{P_{t}}
$$

Given the following production function for intermediate goods:

$$
Y_{t}(i)=N_{t}(i)-F,
$$

we can write real profits as:

$$
O_{t}(i) \equiv\left[\frac{P_{t}(i)}{P_{t}}\right] Y_{t}(i)-\left[\frac{W_{t}}{P_{t}}\right] N_{t}(i)
$$

A firm $i$ sets $P(i)$ in order to solve the following problem:

$$
\begin{aligned}
\max _{\left\{P_{t}^{*}(i)\right\}} E_{t} \sum_{s=0}^{\infty} \alpha^{s} \Lambda_{t, t+s}\left[P_{t}^{*}(i) Y_{t, t+s}(i)-W_{t+s} Y_{t, t+s}(i)\right] \\
\text { s.t }: Y_{t}(i)=\left(\frac{P_{t}^{*}(i)}{P_{t}}\right)^{-\varepsilon} Y_{t}
\end{aligned}
$$

that is:

$$
\max _{\left\{P_{t}^{*}(i)\right\}} E_{t} \sum_{s=0}^{\infty} \alpha^{s} \Lambda_{t, t+s}\left[P_{t}^{*}(i)\left(\frac{P_{t}^{*}(i)}{P_{t}}\right)^{-\varepsilon} Y_{t}-W_{t}\left(\frac{P_{t}^{*}(i)}{P_{t}}\right)^{-\varepsilon} Y_{t}\right]
$$

The FOC is given by:

$$
E_{t} \sum_{s=0}^{\infty} \alpha^{s} \Lambda_{t, t+s}\left[P_{t}^{*}(i)-\frac{\varepsilon}{\varepsilon-1} W_{t+s}\right]=0
$$

\section{Appendix B. Steady States}

The Euler equation in the steady state gives:

$$
R=\frac{1}{\beta}
$$


In the steady state, from the FOC of the price setting in the intermediate goods firm's problem, we have for the real wage:

$$
\frac{W}{P}=\frac{\varepsilon-1}{\varepsilon}
$$

we can rewrite (A14) as:

$$
\frac{W}{P}=\frac{Y}{N} \frac{1+F_{Y}}{1+\mu}
$$

The ratio of profits to output is given by:

$$
O_{Y} \equiv \frac{\mu-F_{Y}}{1+\mu}
$$

We assume, in the steady state, that:

$$
N_{N}=N_{A}=N
$$

Because of preference homogeneity, we need to ensure that steady-state consumption shares are also equal across groups. This can be seen comparing the two labour decision equations evaluated in the steady state:

$$
\frac{C_{A}}{L}=\frac{1-\tau}{\varphi} \frac{W}{P}=\frac{C_{N}}{L}
$$

implying:

$$
C_{A}=C_{N}=C
$$

The steady-state coefficients needed for our log-linear approximation above are fully determined as:

$$
\begin{gathered}
(1-\tau) \frac{W}{P} \frac{N}{Y}=(1-\tau) \frac{1+F_{Y}}{1+\mu} \\
\frac{C_{N}}{Y}=(1-\tau) \frac{1+F_{Y}}{1+\mu}-T_{Y} \\
T_{Y}=G_{Y}-\tau \\
\frac{C_{A}}{Y}=(1-\tau) \frac{1}{1-\lambda}\left(1-\lambda \frac{1+F_{Y}}{1+\mu}\right)-T_{Y}
\end{gathered}
$$

We thus achieve equalization of steady-state consumption shares by making an assumption on technology. Specifically, we ensure that asset income in the steady state is zero. This requires assuming that the fixed cost of production is characterised by:

$$
F_{Y}=\mu
$$

Substituting in (A22) gives:

$$
\frac{C_{A}}{Y}=\frac{C_{N}}{Y}=1-\tau-T_{Y}=1-G_{Y}
$$

We want to find hours in steady state. Given the equalization of hours and consumption between the two groups and normalizing $P=1$, the intratemporal optimality condition implies:

$$
(1-\tau) W N-T=\frac{(1-\tau)}{\varphi} W(1-N)
$$


dividing by $Y$ and using (A20) and the expression for the fixed cost, we obtain the following expression for the steady-state hours:

$$
\frac{N}{1-N}=\frac{1}{\varphi} \frac{1-\tau}{1-G_{Y}}
$$

Given $\tau$ and $G_{Y}$, we chose the steady state $N$ to match average hours worked. From (A27), this implies a unique value for $\varphi$.

\section{Appendix C. The Log-Linearized Model}

Below, we show the log-linearized equations of our model around the non-stochastic steady state. We denote by small letters the log deviation of a variable from its steady-state value, while for any variable $X_{t}, X$ stands for its steady-state value and $X_{Y}$ its steady-state share in output, $X / Y$.

The log-linearized Euler equation for asset-holders is given by:

$$
c_{A, t}=E_{t} c_{A, t+1}-\frac{1}{\sigma}\left(r_{t}-E_{t} \pi_{t+1}\right)+\left(\frac{1}{\sigma}-1\right)\left(1+\frac{T_{Y}}{1-G_{Y}}\right)\left(E_{t} n_{A, t+1}-n_{A, t}\right)
$$

The log-linearization of the labour decision equation for asset holders is given by:

$$
\frac{N}{1-N} n_{A, t}=w_{t}-c_{A, t}
$$

The log-linearized labour decision equation for non-asset holders is equal to:

$$
\frac{N}{1-N} n_{N, t}=w_{t}-c_{N, t}
$$

The consumption for non-asset holders is obtained log-linearizing their budget constraint and is given by:

$$
\left(1-G_{Y}\right) c_{N, t}=(1-\tau)\left(w_{t}+n_{N, t}\right)-T_{Y} t_{t}
$$

From the last two relations, we obtain a reduced-form labour supply for non-asset holders:

$$
n_{N, t}=\frac{\varphi}{1+\varphi}\left[\frac{-T_{Y}}{1-G_{Y}+T_{Y}}\right]\left(w_{t}-t_{t}\right)
$$

The log-linearized expression for aggregate hours is given by:

$$
n_{t}=\lambda n_{N, t}+(1-\lambda) n_{A, t}
$$

The log-linearized expression for aggregate consumption is given by:

$$
c_{t}=\lambda c_{N, t}+(1-\lambda) c_{A, t}
$$

The log-linearized aggregate production function is given by:

$$
y_{t}=\left(1+F_{Y}\right) n_{t}
$$

We note that the share of the fixed cost $F$ in the steady-state output governs the degree of increasing returns to scale. The log-linearized new-Keynesian Phillips curve is given by:

$$
\pi_{t}=\beta E_{t} \pi_{t+1}+\frac{(1-\alpha)(1-\alpha \beta)}{\alpha} w_{t}
$$


In both models of aggregate government spending and disaggregated non-military and military components, the log-linearization of the budget constraint around a steady state with zero debt and a balanced primary budget gives the following expression:

$$
\beta b_{t+1}=b_{t}+G_{Y} g_{t}-T_{T} t_{t}-\tau y_{t}
$$

Moreover, in the model with disaggregated non-military and military spending, we have that:

$$
g_{t} G_{Y}=N M_{Y} n m_{t}+M_{Y} m_{t}
$$

The log-linearized structural primary deficit is given by:

$$
d_{s, t}=G_{Y} g_{t}-T_{Y} t_{t}
$$

Finally, the log-linearized goods market clearing can be written as:

$$
y_{t}=g_{t} G_{Y}+c_{t}\left(1-G_{Y}\right)
$$




\section{Appendix D. Diagnostic Tests}

\section{Appendix D.1. Prior and Posterior Distributions}

S1 (1954:Q3-1979:Q2)
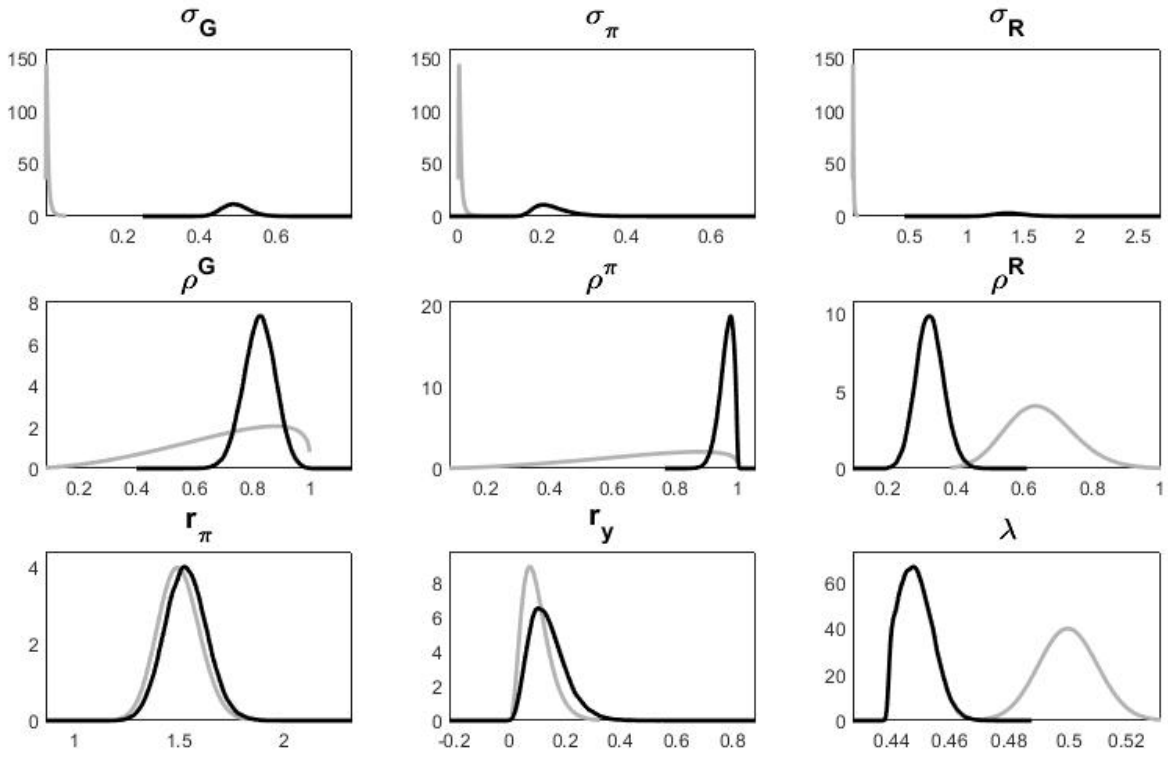

S2 (1983:Q1-2008:Q2)
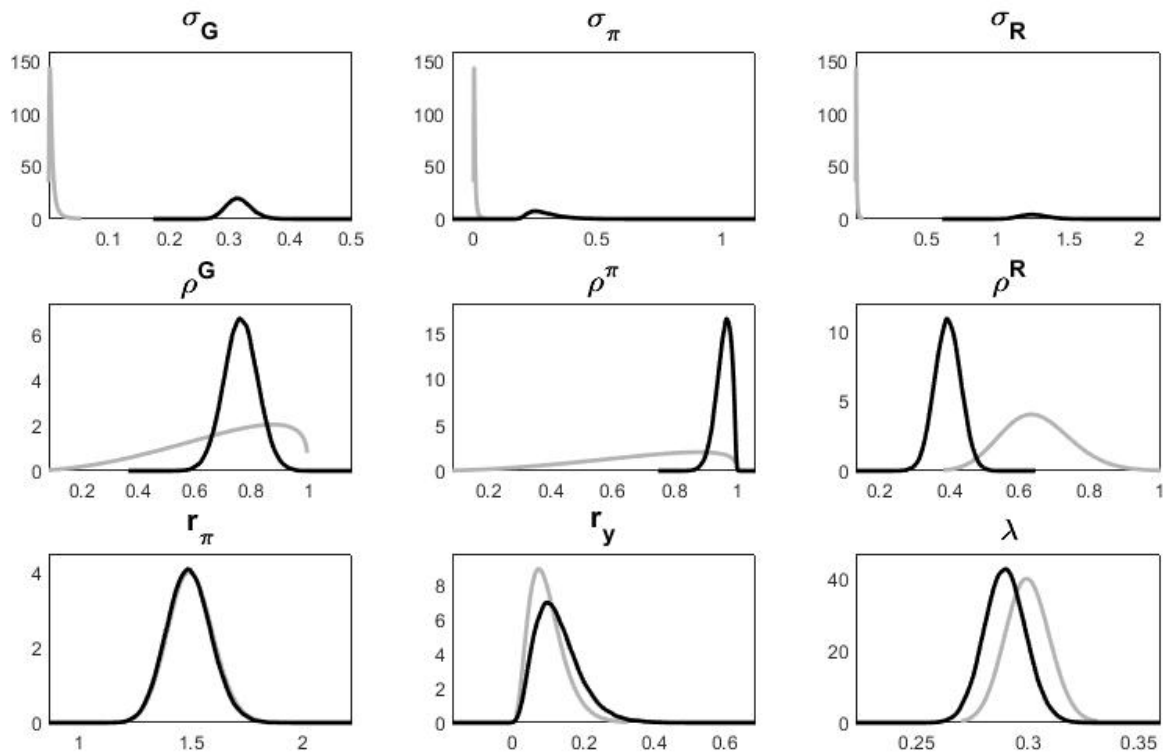

Figure A1. Total government spending model. Notes: In the above graphs, the grey lines represent the prior distributions, whereas the black lines correspond to the posterior distributions. 
S1 (1954:Q3-1979:Q2)
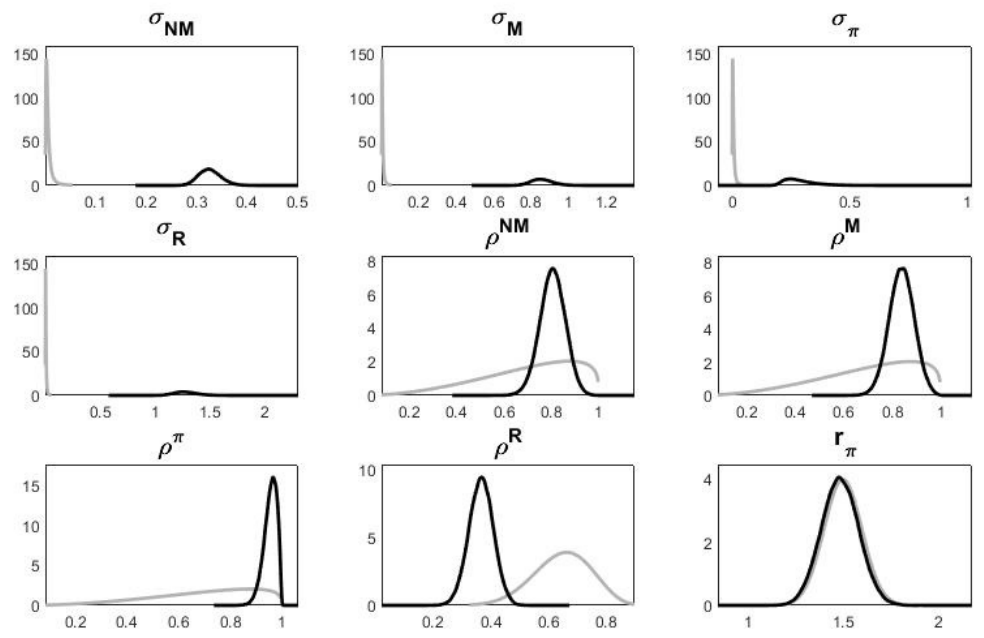

$r_{y}$
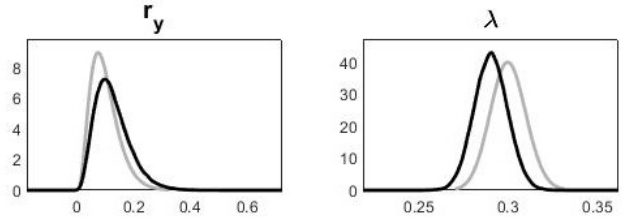

S2 (1983:Q1-2008:Q2)
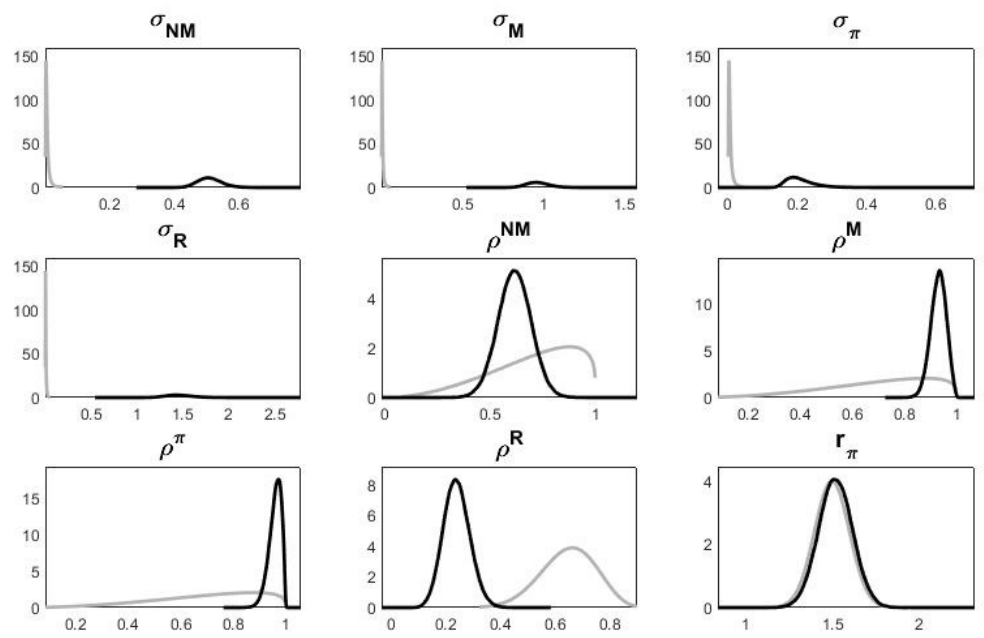

$r_{y}$
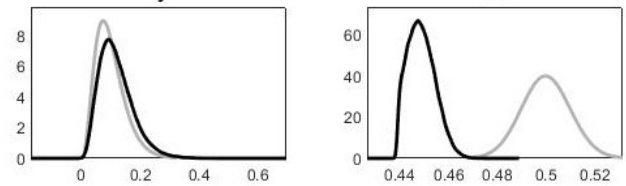

Figure A2. Non-military and military spending model. Notes: In the above graphs, the grey lines represent the prior distributions, whereas the black lines correspond to the posterior distributions. 
Appendix D.2. Monte Carlo Markov Chain Univariate Diagnostics
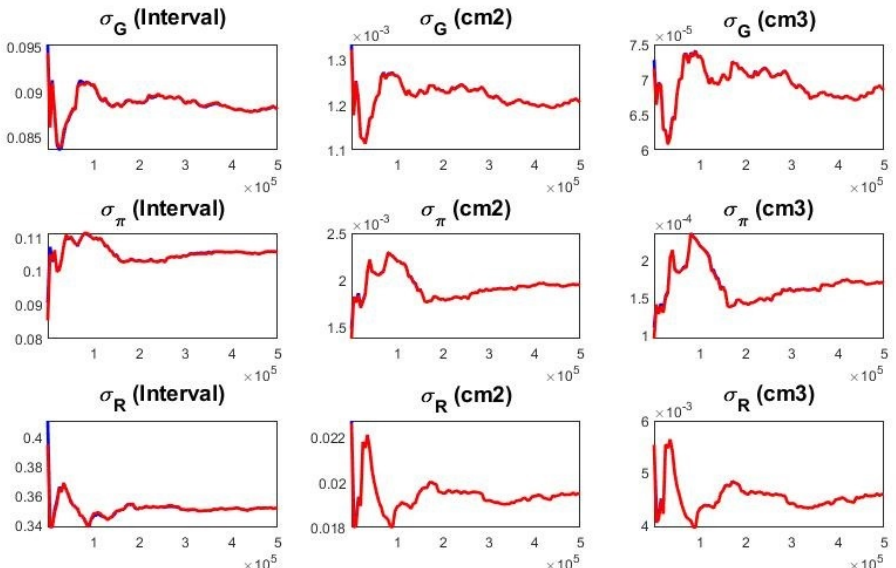

$\sigma_{\mathrm{R}}(\mathrm{cm} 2)$
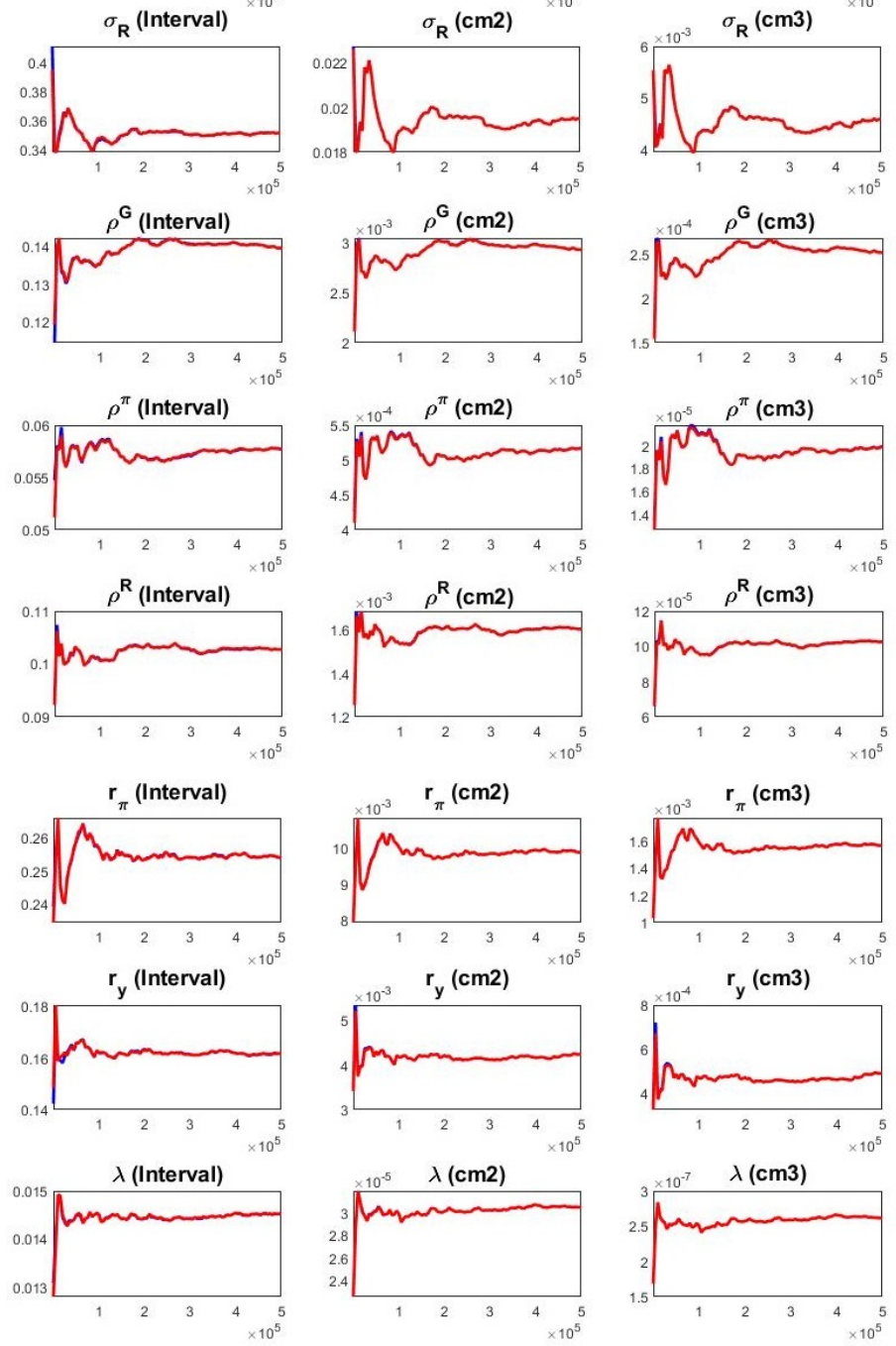

Figure A3. Total government spending model: S1 (1954:Q3-1979:Q2). Notes: In the above graphs, the blue lines represent the $80 \%$ interval range based on the pooled draws from all sequences, whereas the red lines indicate the mean interval based on the draws of the individual sequences. The first column shows the convergence diagnostics for the $80 \%$ interval. The second and the third column with labels denote an estimate of the same statistics for the second and third central moments. 

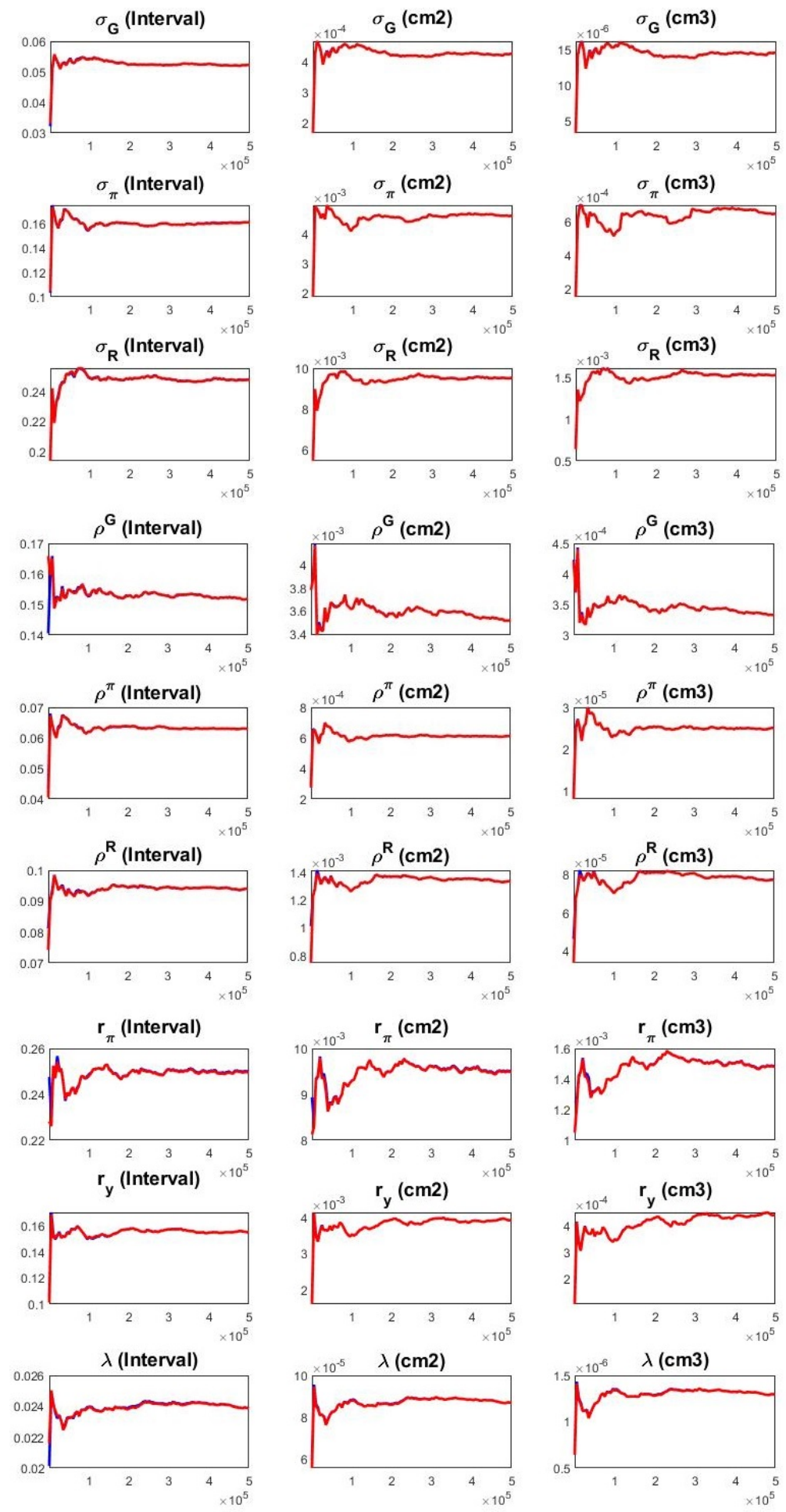

Figure A4. Total government spending model, S2 (1983:Q1-2008:Q2). Notes: In the above graphs, the blue lines represent the $80 \%$ interval range based on the pooled draws from all sequences, whereas the red lines indicate the mean interval based on the draws of the individual sequences. The first column shows the convergence diagnostics for the $80 \%$ interval. The second and the third column with labels denote an estimate of the same statistics for the second and third central moments. 

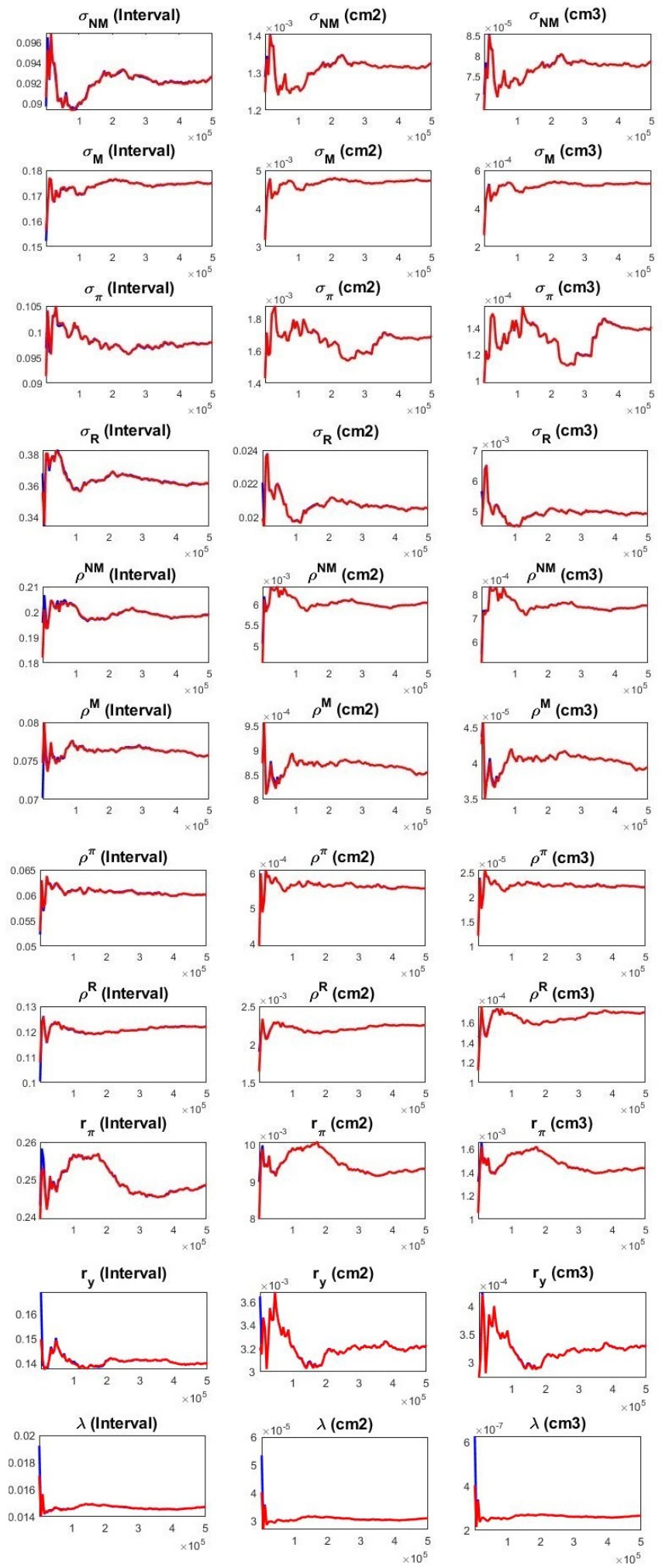

Figure A5. Non-military and military spending model: S1 (1954:Q3-1979:Q2). Notes: In the above graphs, the blue lines represent the $80 \%$ interval range based on the pooled draws from all sequences, whereas the red lines indicate the mean interval based on the draws of the individual sequences. The first column shows the convergence diagnostics for the $80 \%$ interval. The second and the third column with labels denote an estimate of the same statistics for the second and third central moments. 

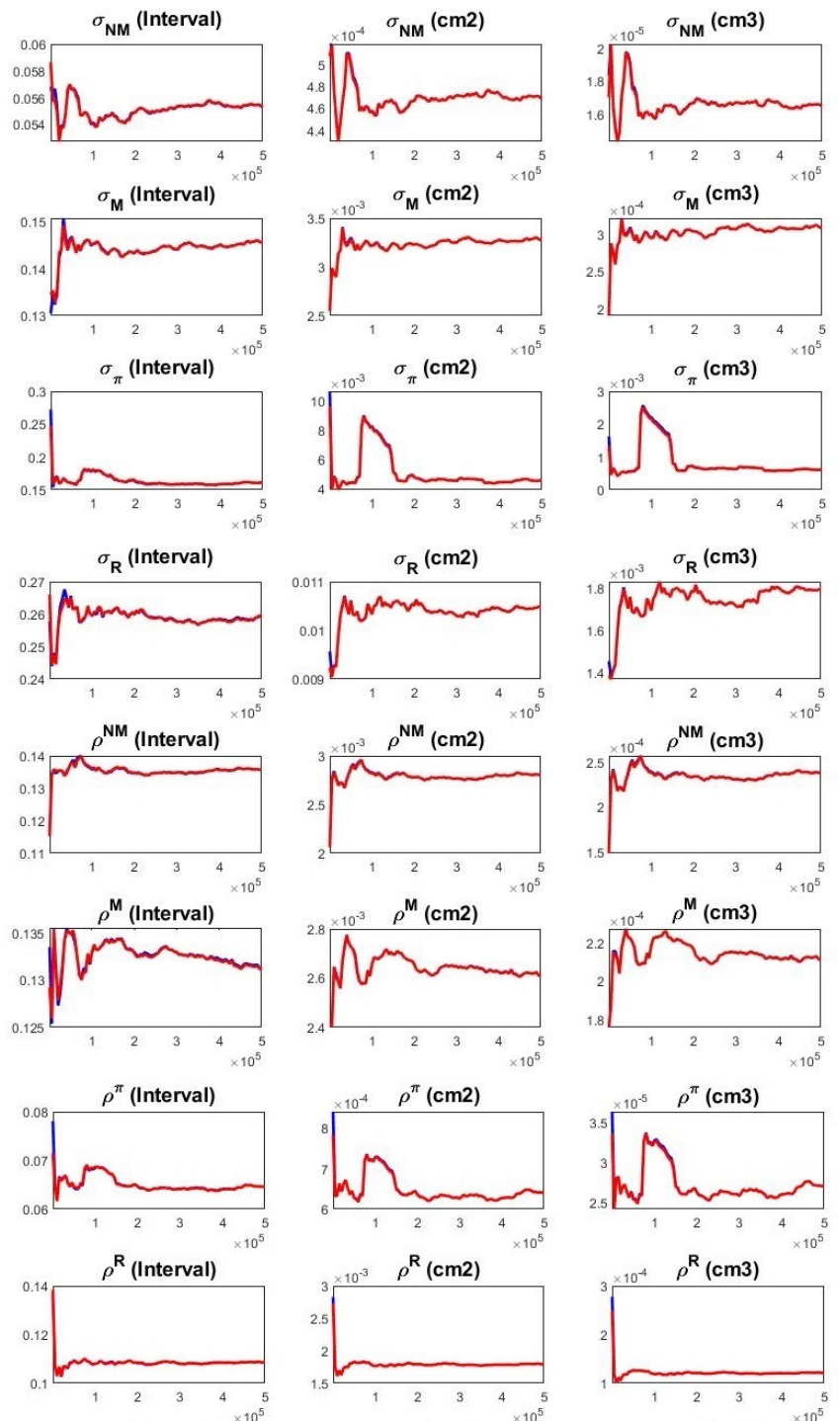

$\mathbf{r}_{\pi}$ (Interval)

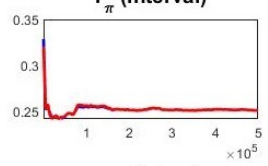

$r_{\pi}(\mathrm{cm} 2)$

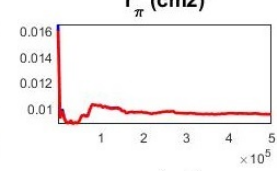

$\mathrm{r}_{\pi}(\mathrm{cm} 3)$
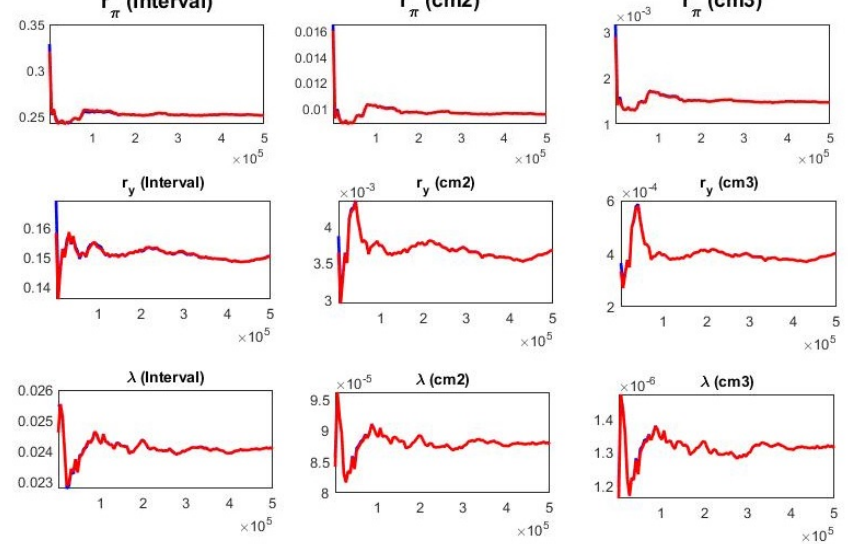

Figure A6. Non-military and military spending model: S2 (1983:Q1-2008:Q2). Notes: In the above graphs, the blue lines represent the $80 \%$ interval range based on the pooled draws from all sequences, whereas the red lines indicate the mean interval based on the draws of the individual sequences. The first column shows the convergence diagnostics for the $80 \%$ interval. The second and the third column with labels denote an estimate of the same statistics for the second and third central moments. 
Appendix D.3. Multivariate Convergence Diagnostics

S1 (1954:Q3-1979:Q2)
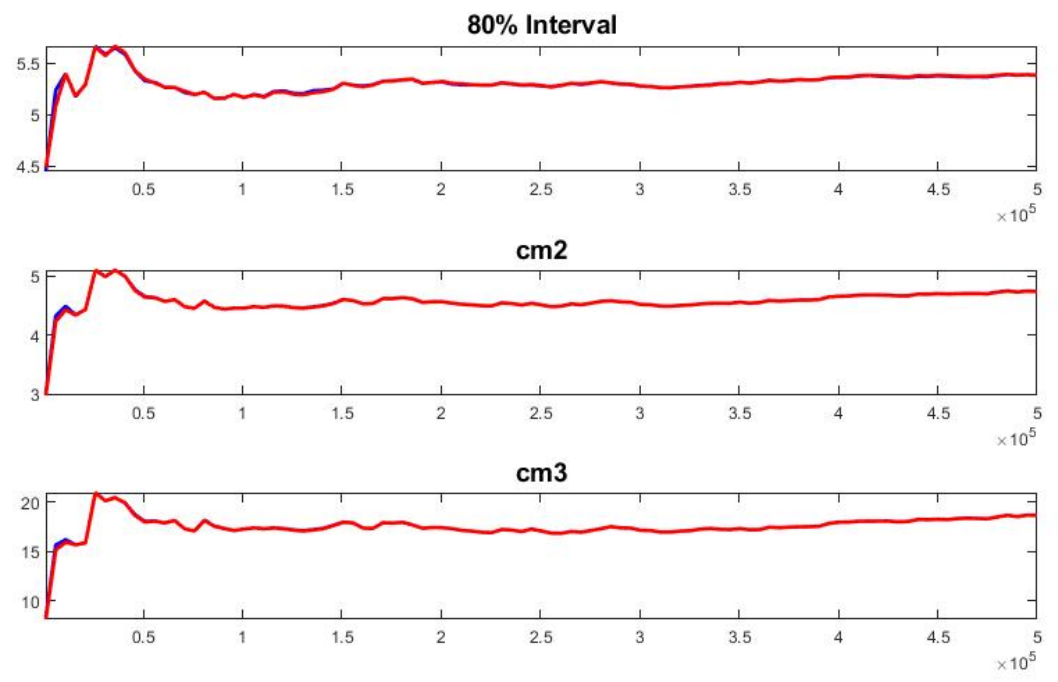

S2 (1983:Q1-2008:Q2)
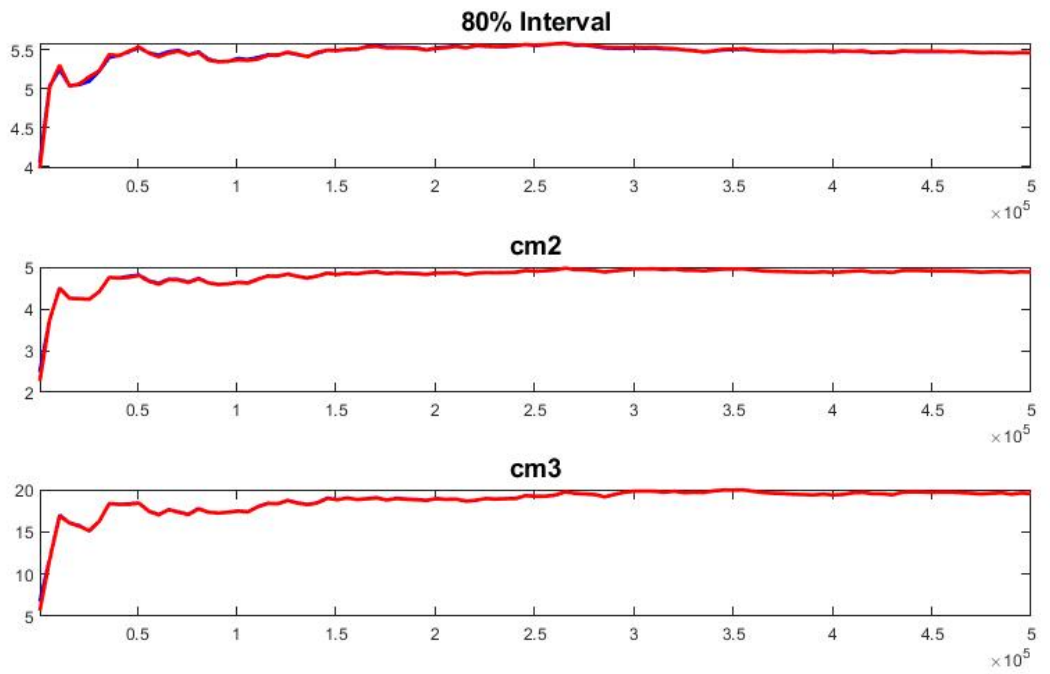

Figure A7. Total government spending model. Notes: In the above graphs, the diagnostics is based on the range of the posterior likelihood function. 
S1 (1954:Q3-1979:Q2)
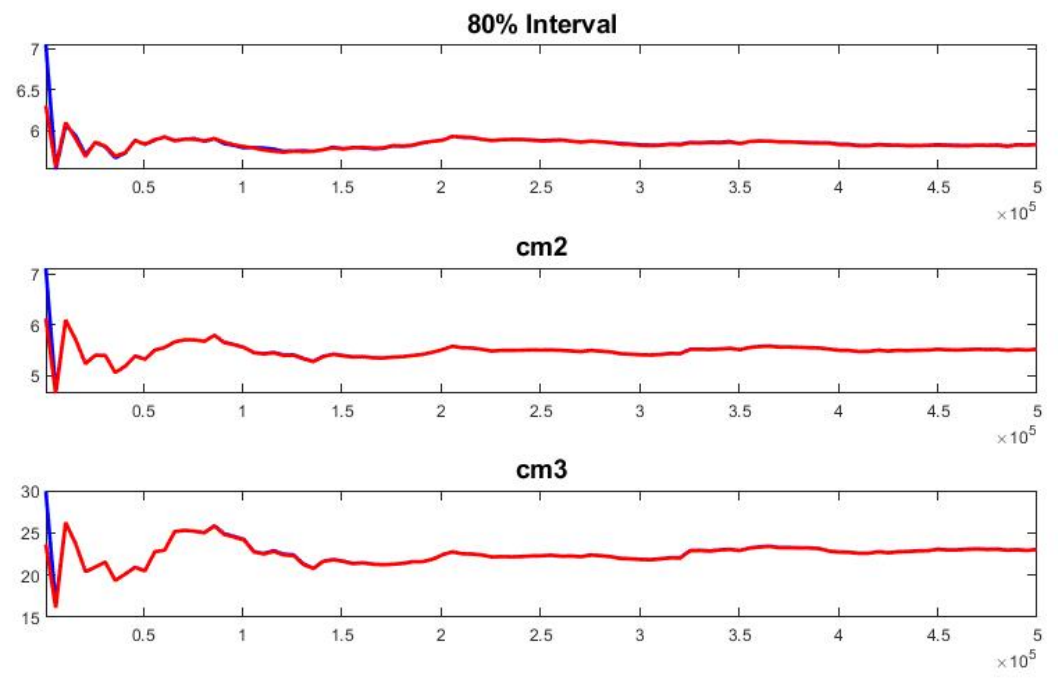

S2 (1983:Q1-2008:Q2)
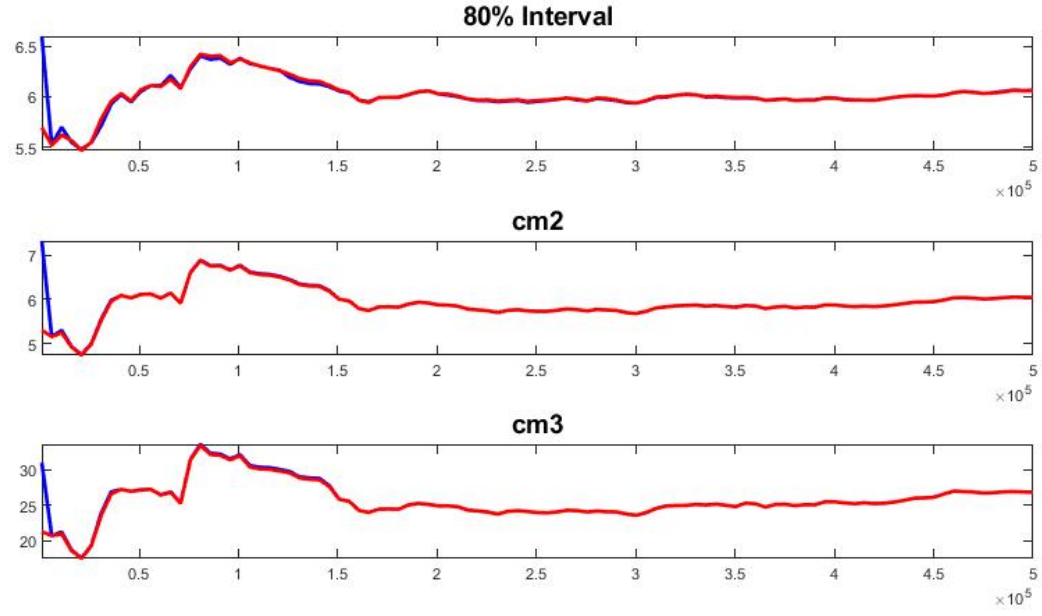

Figure A8. Non-military and military spending model. Notes: In the above graphs, the diagnostics is based on the range of the posterior likelihood function. 
S1 (1954:Q3-1979:Q2)
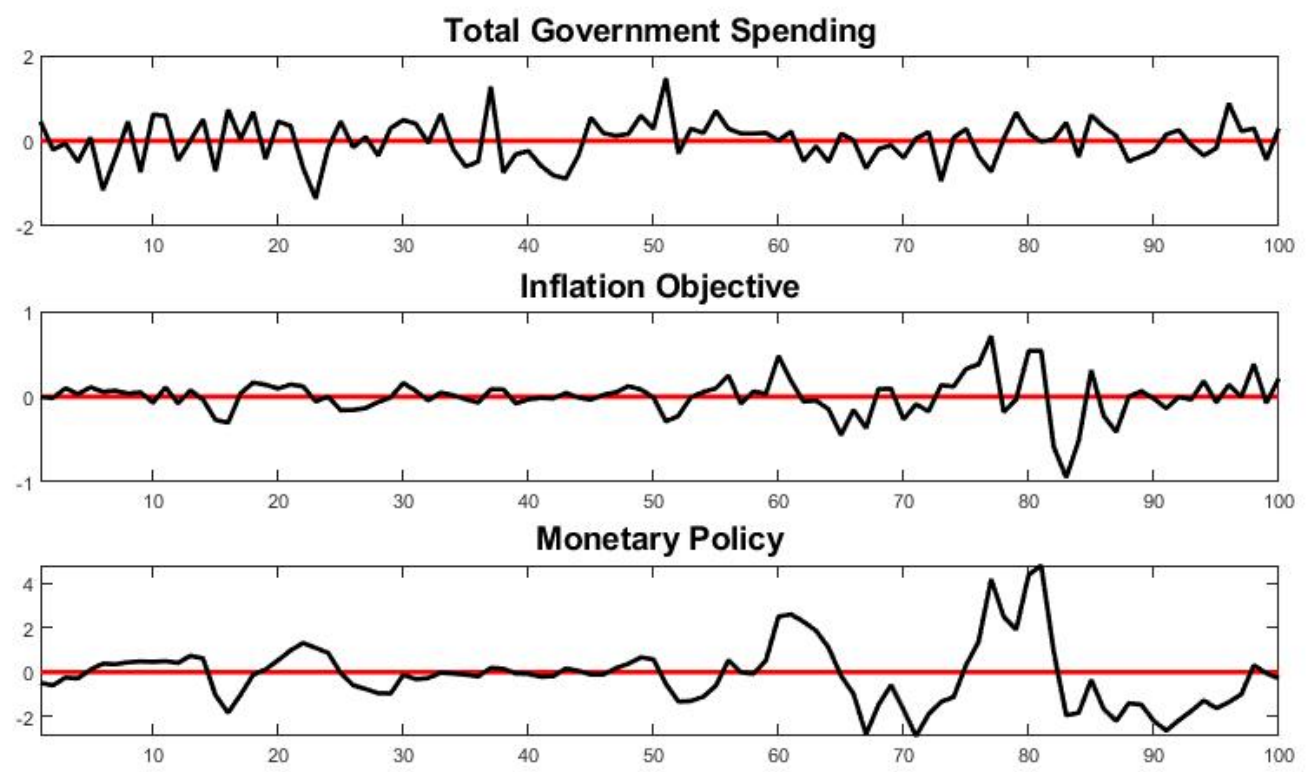

S2 (1983:Q1-2008:Q2)

Total Government Spending
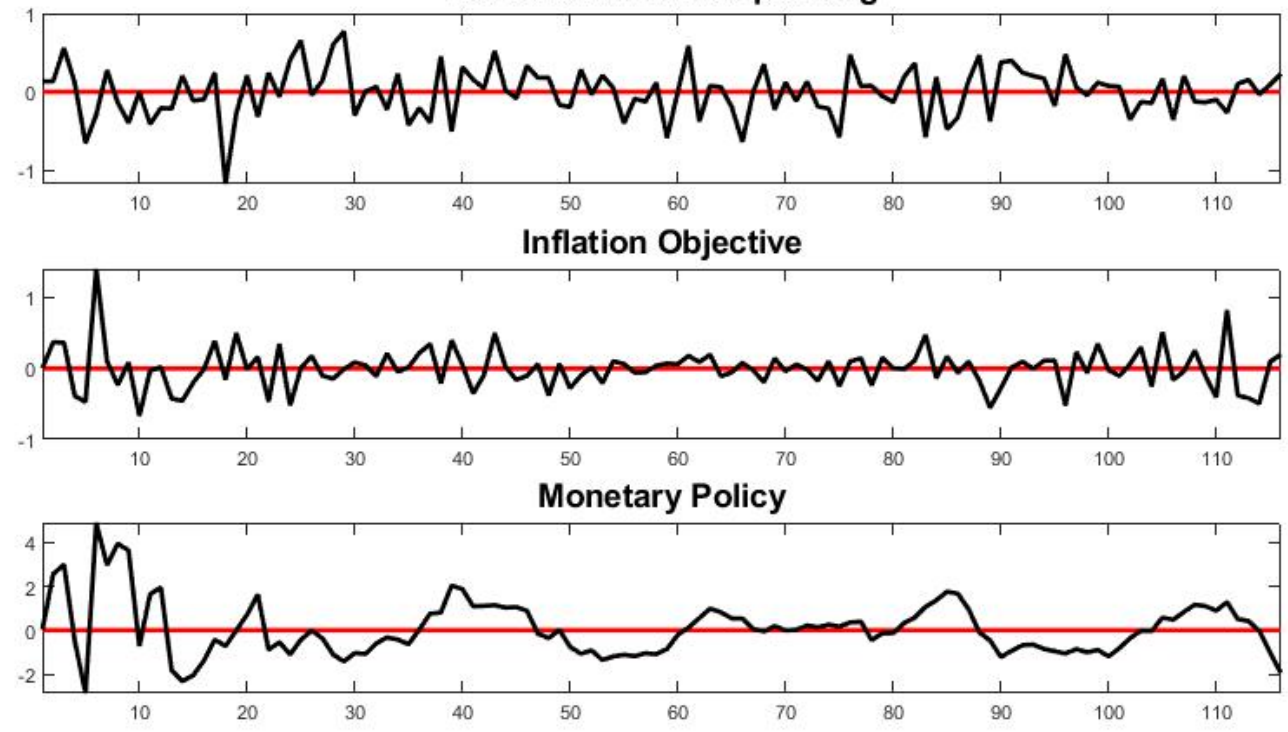

Figure A9. Total government spending model. Notes: In the above graphs, the black line represents the estimate of the smoothed structural shocks. 
S1 (1954:Q3-1979:Q2)
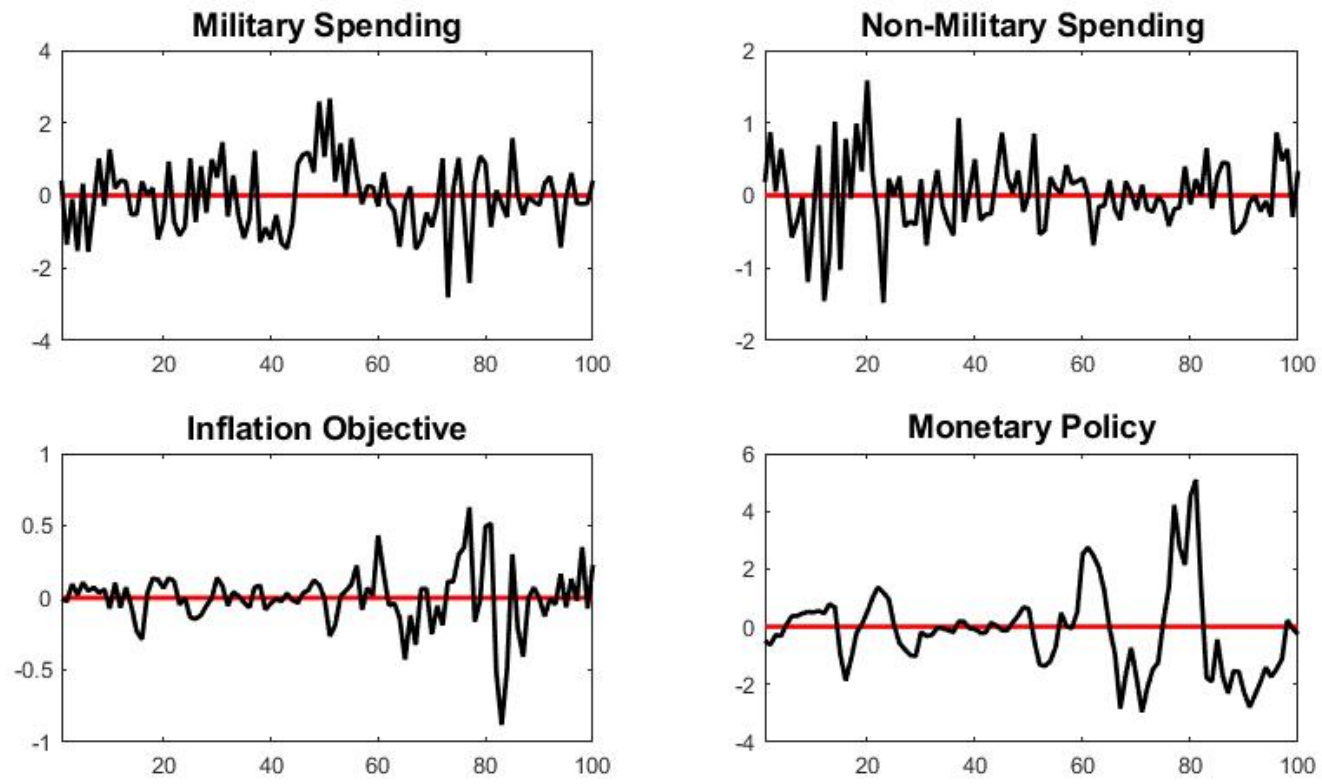

S2 (1983:Q1-2008:Q2)
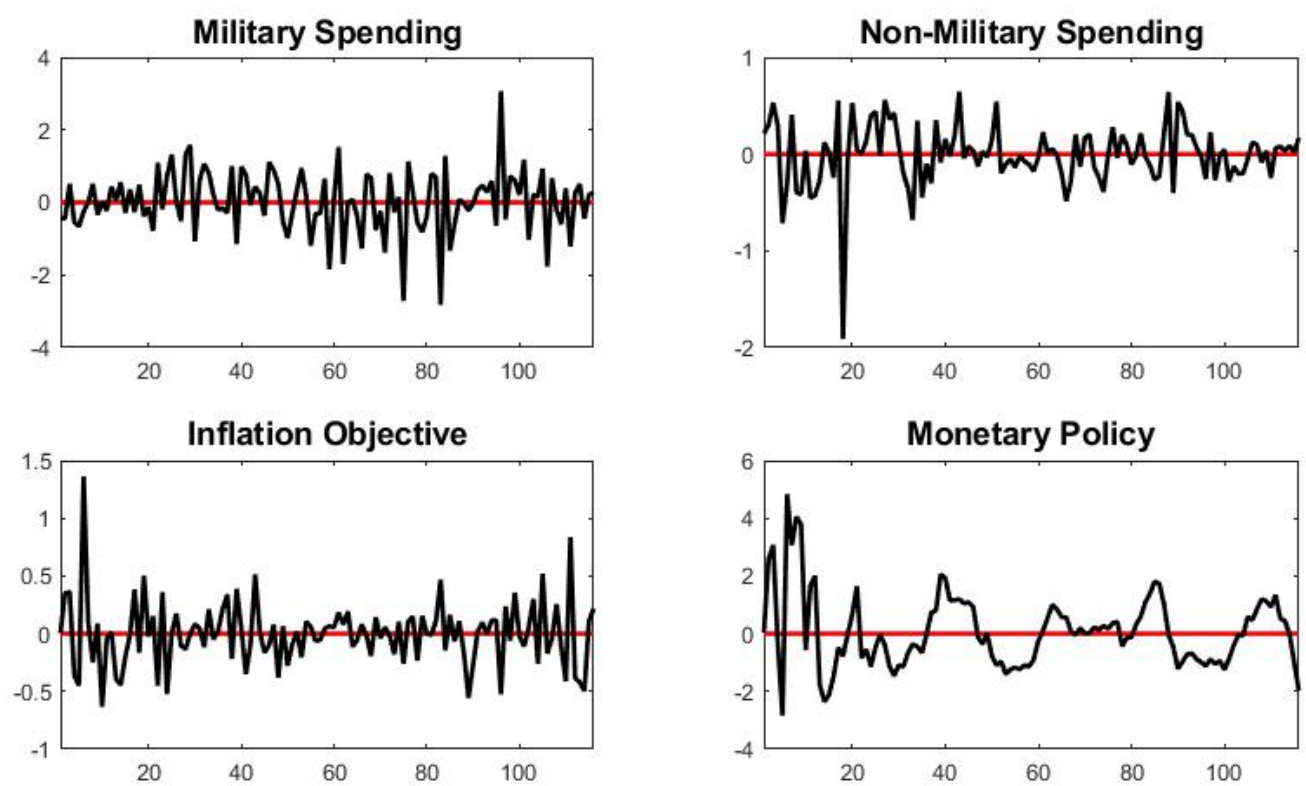

Figure A10. Non-military and military spending model. Notes: In the above graphs, the black line represents the estimate of the smoothed structural shocks. 
S1 (1954:Q3-1979:Q2)
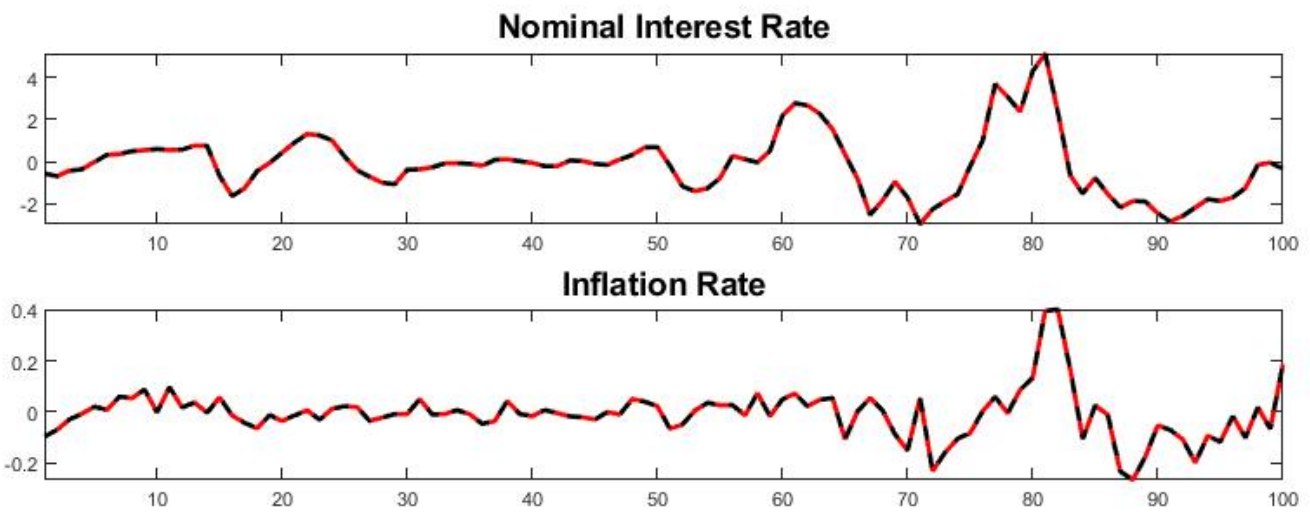

Total Government Spending

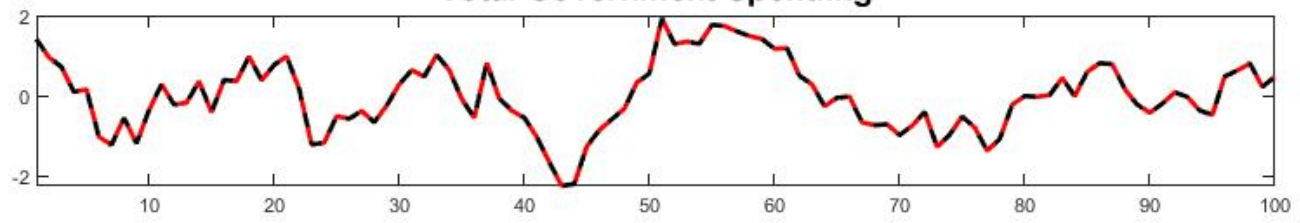

S2 (1983:Q1-2008:Q2)

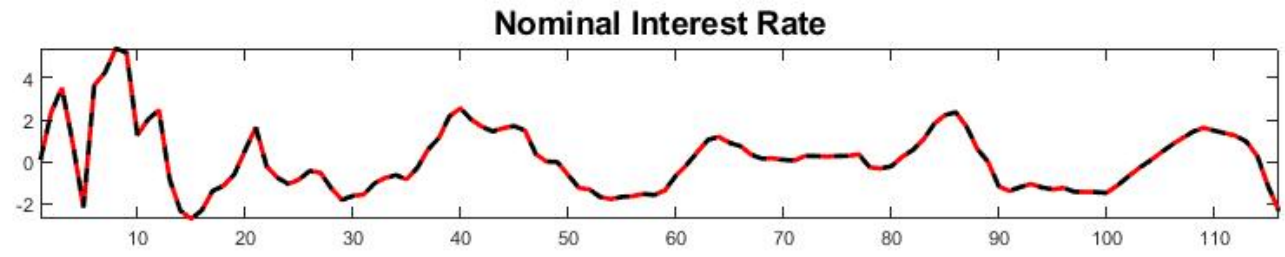

Inflation Rate

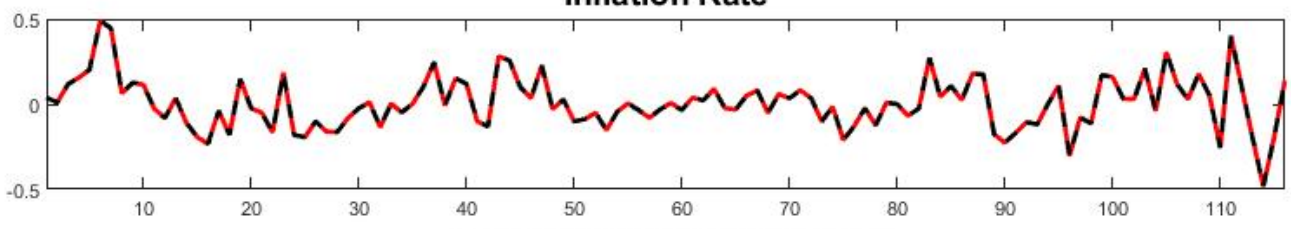

Total Government Spending

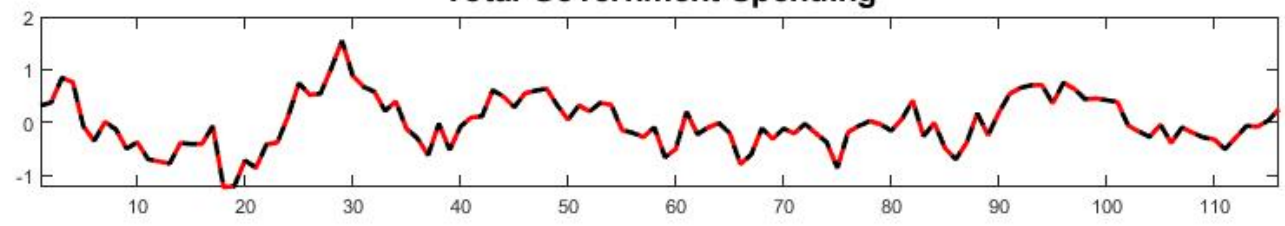

Figure A11. Total government spending model. Notes: In the above graphs, the dotted black lines indicate the observed data. The red lines indicate the estimates of the smoothed variables. 
S1 (1954:Q3-1979:Q2)
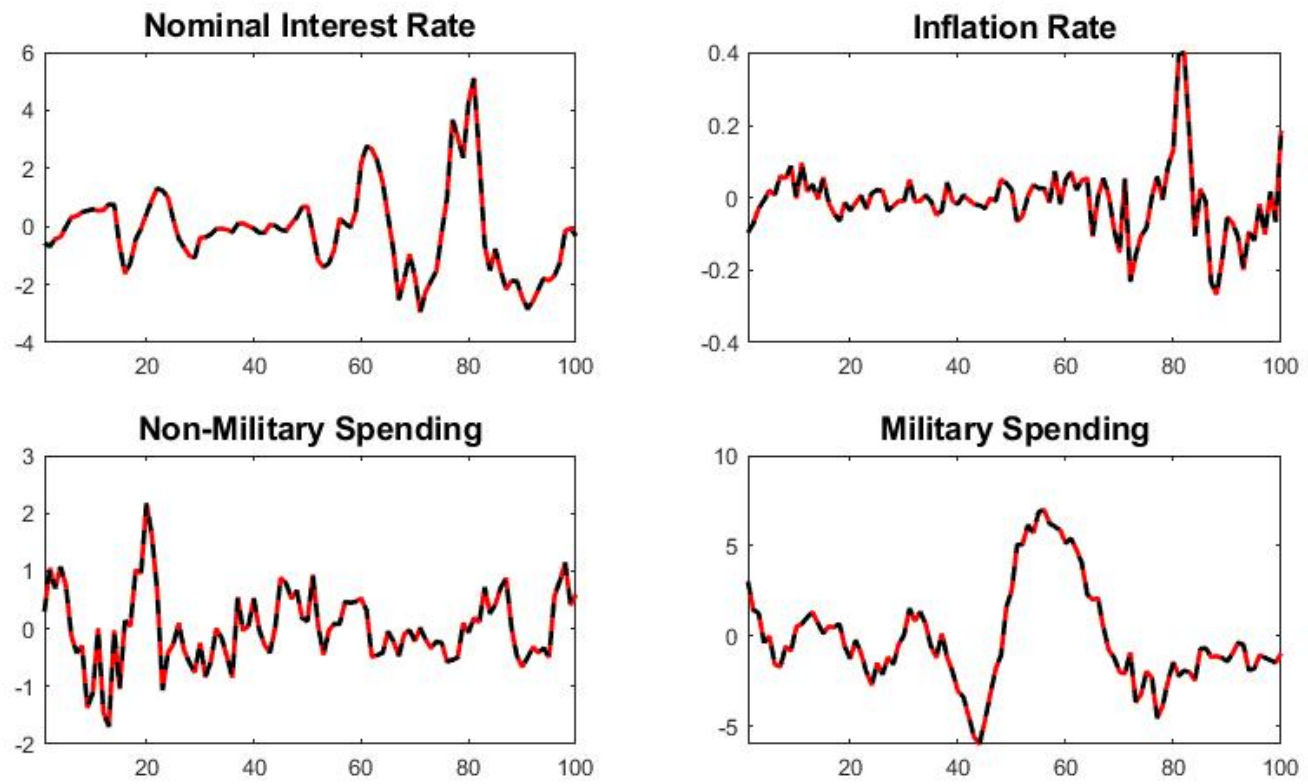

S2 (1983:Q1-2008:Q2)
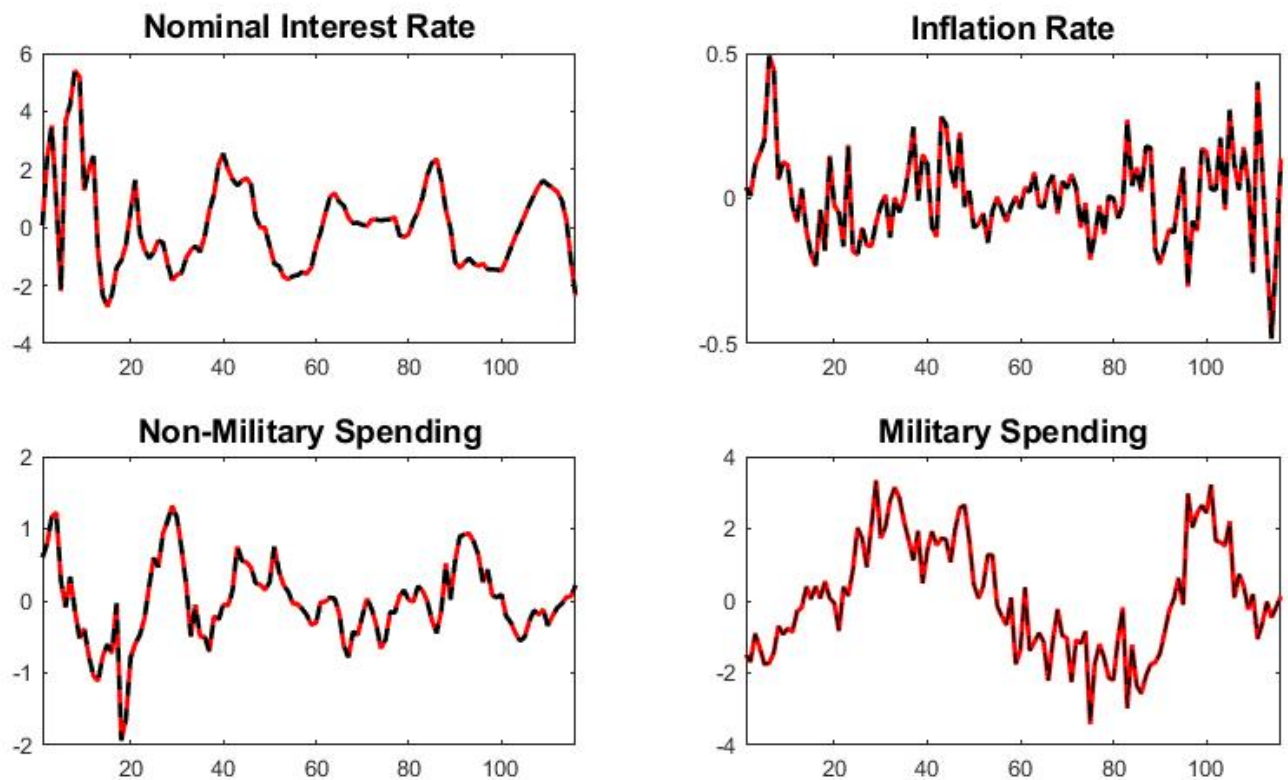

Figure A12. Non-military and military spending model. Notes: In the above graphs, the dotted black lines indicate the observed data. The red lines indicate the estimates of the smoothed variables. 

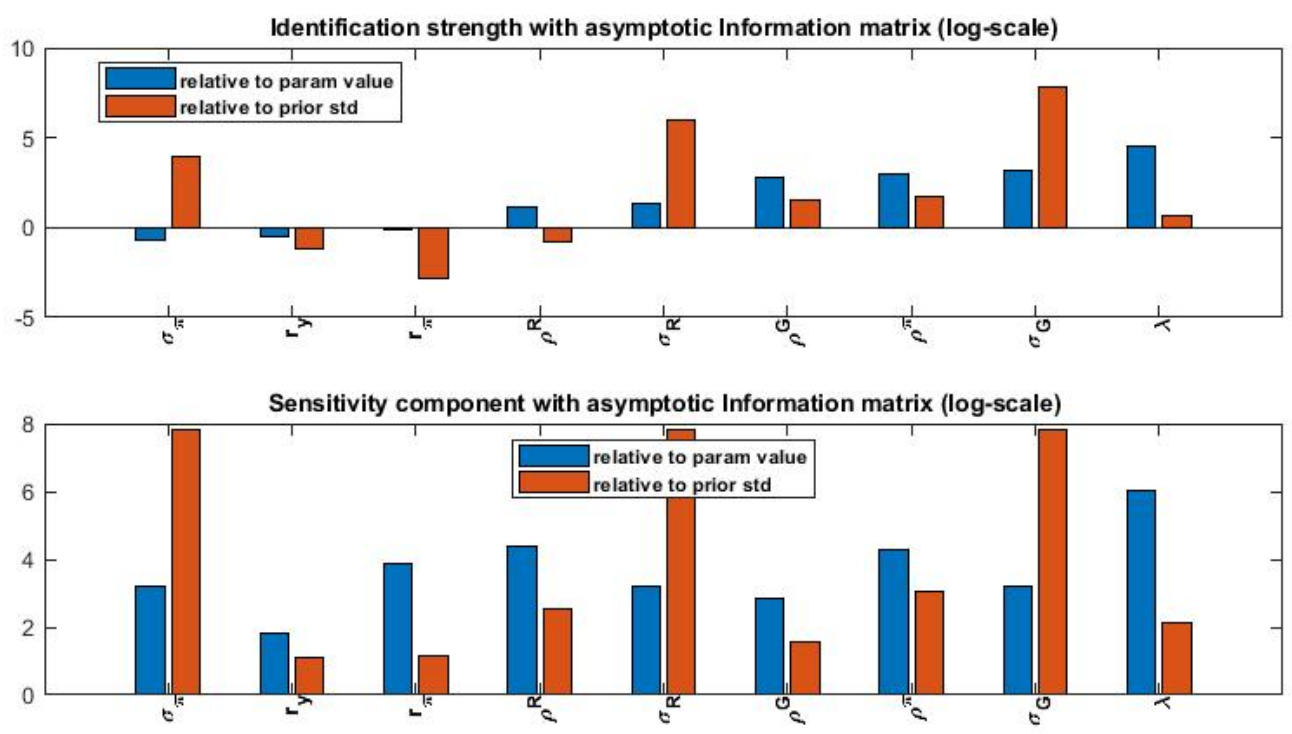

S2 (1983:Q1-2008:Q2)
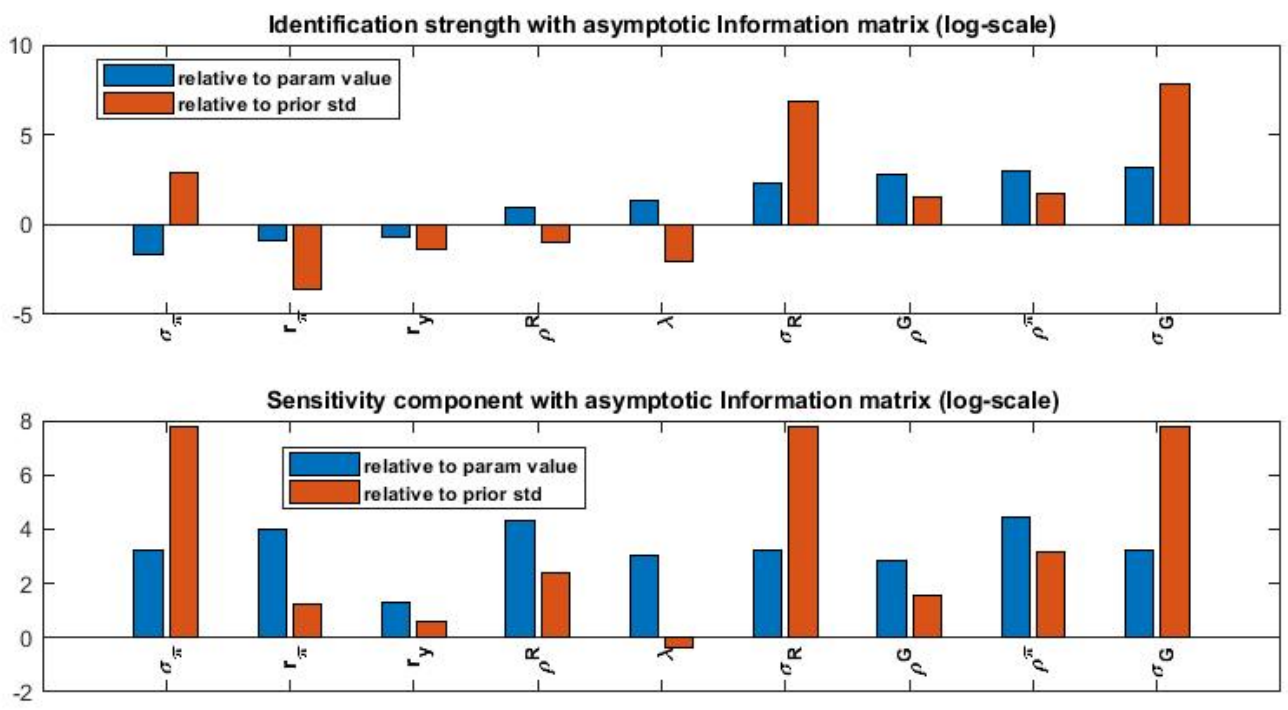

Figure A13. Total government spending model. Notes: In the above graphs, blue bars indicate the identification strength of the parameters based on their prior means, whereas orange bars denote the identification strength of the parameters based on their standard deviations. 
S1 (1954:Q3-1979:Q2)
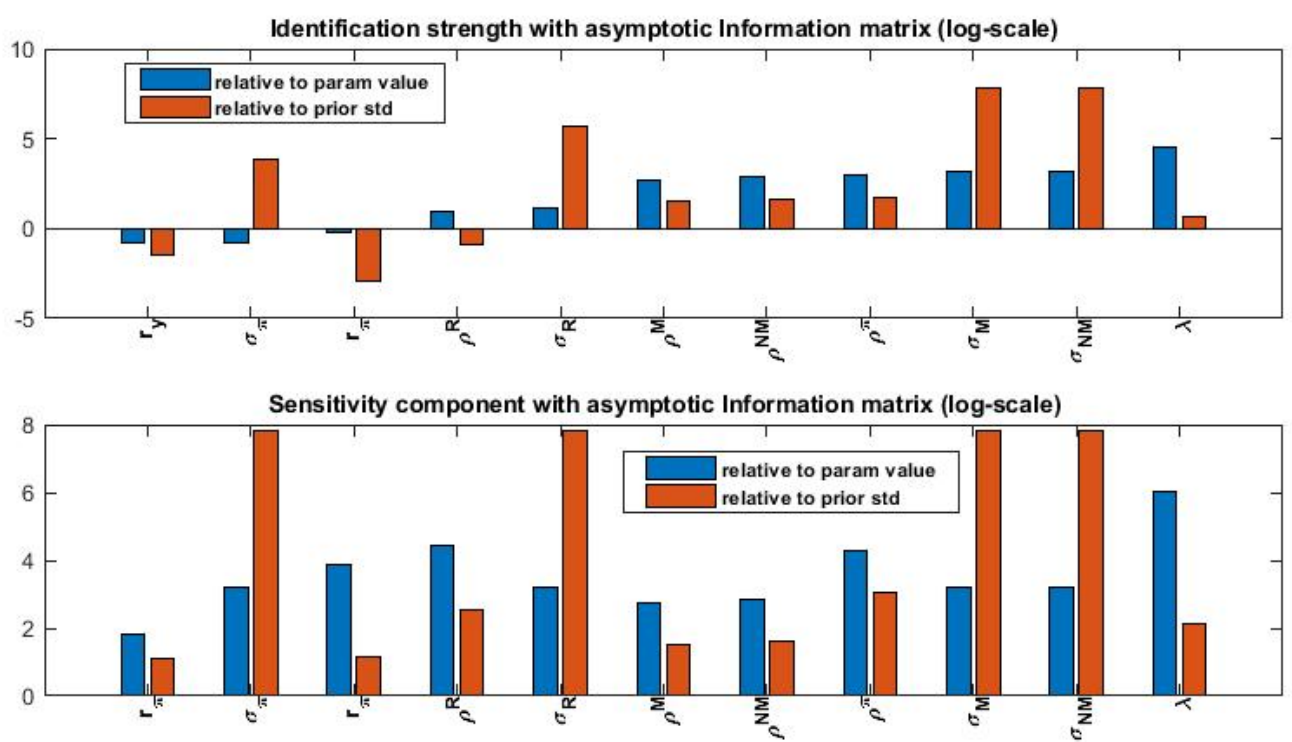

S2 (1983:Q1-2008:Q2)
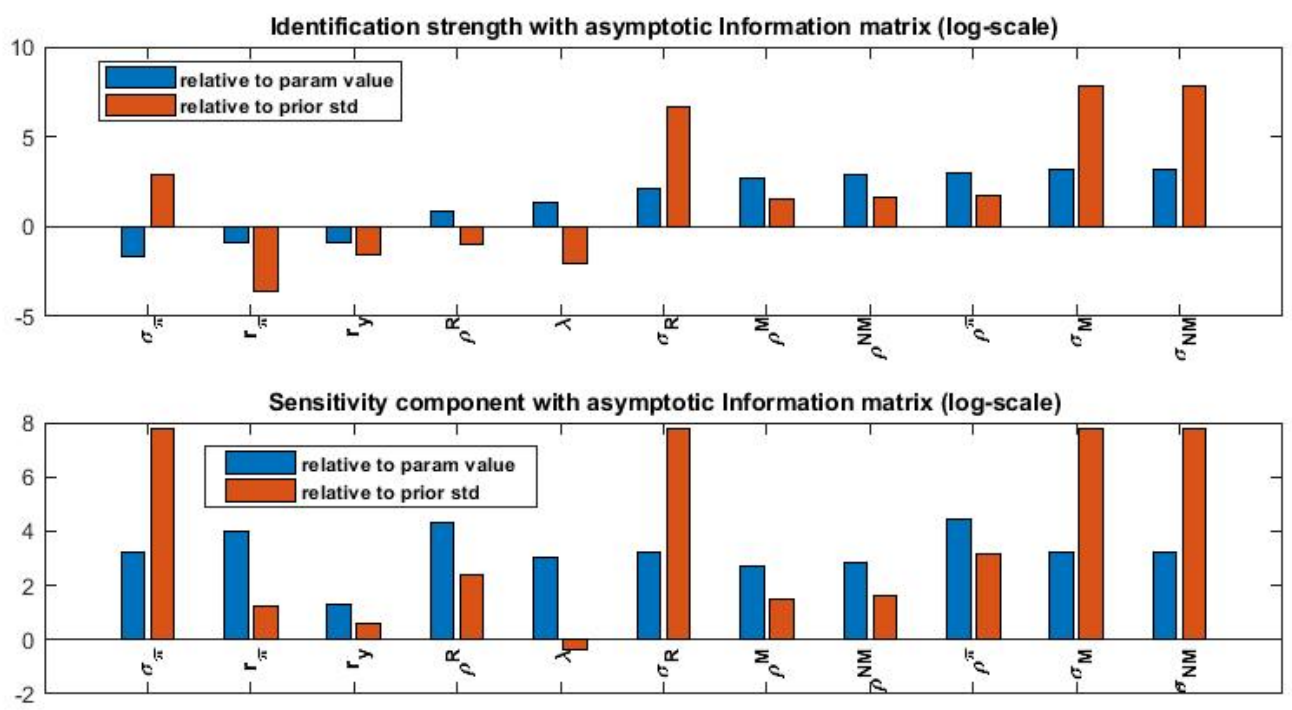

Figure A14. Non-military and military spending model. Notes: In the above graphs, blue bars indicate the identification strength of the parameters based on their prior means, whereas orange bars denote the identification strength of the parameters based on their standard deviations. 
Appendix E. Estimated Impulse Response Functions

S1 (1954:Q3-1979:Q2)

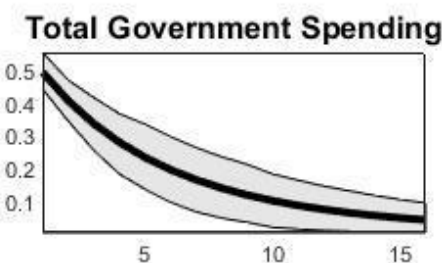

Aggregate Wage

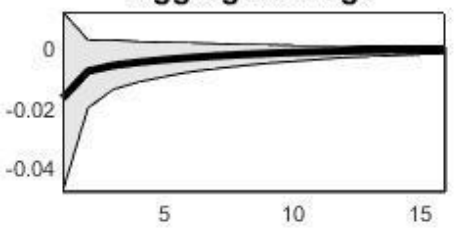

Total Government Spending
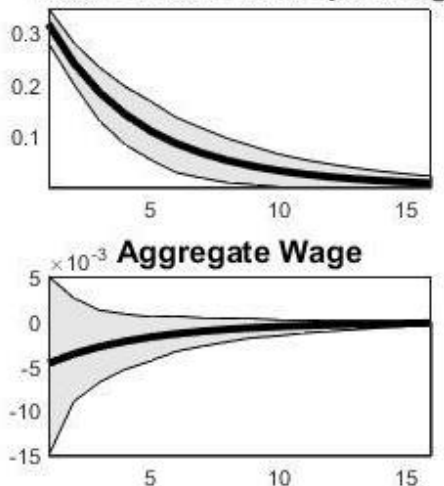

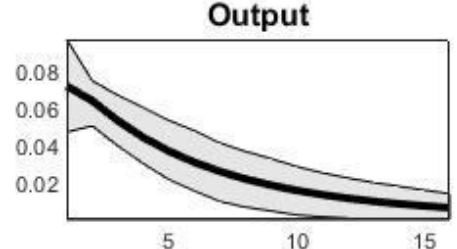

Private Consumption

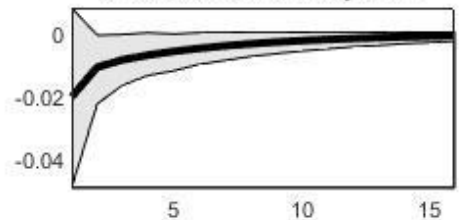

S2 (1983:Q1-2008:Q2)

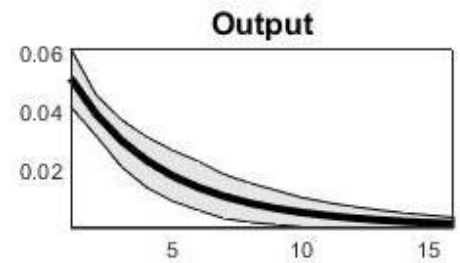

Private Consumption

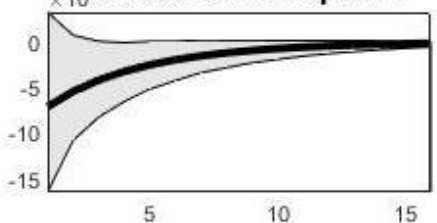

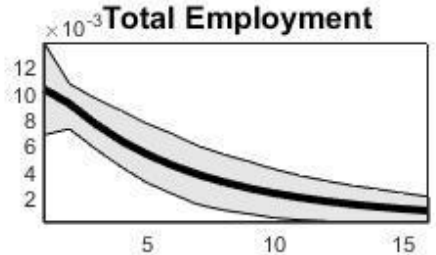
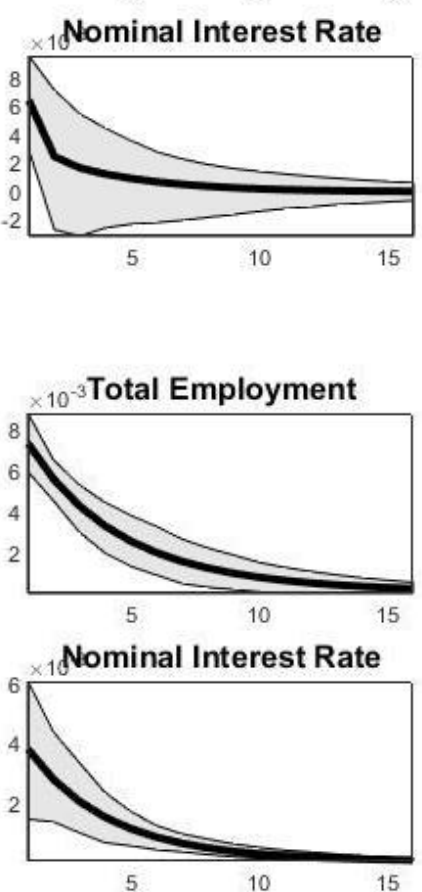

Figure A15. Total government spending shock. Notes: The above graphs show the responses of the key variables together with their $95 \%$ confidence intervals. 
S1 (1954:Q3-1979:Q2)
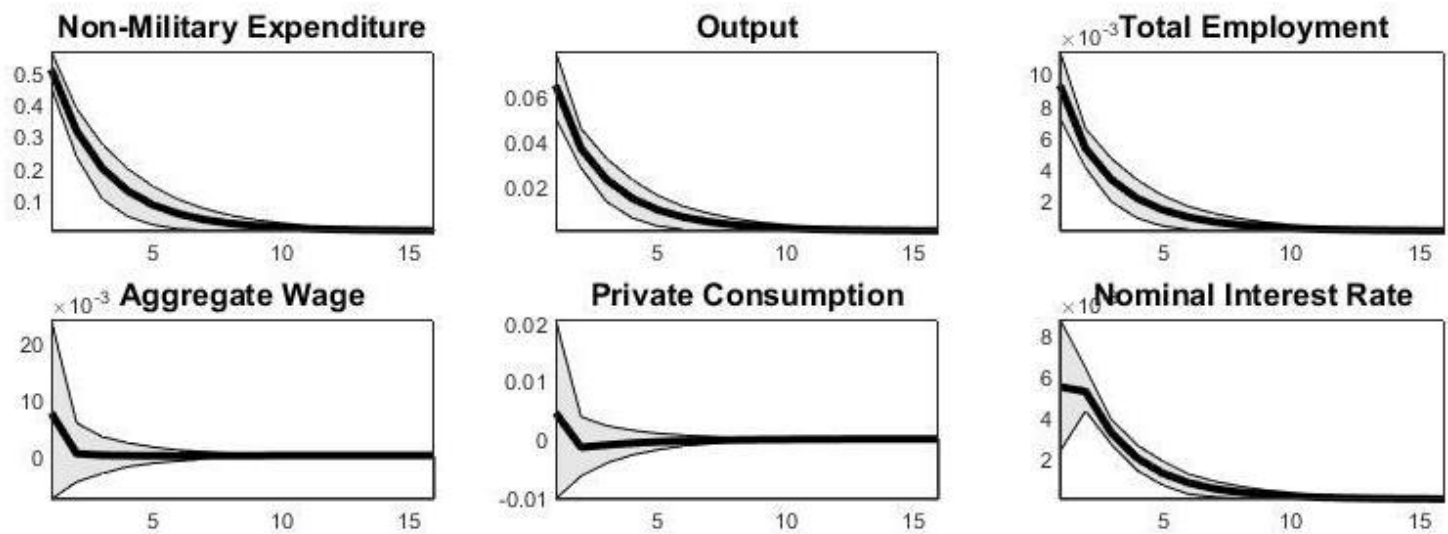

S2 (1983:Q1-2008:Q2)
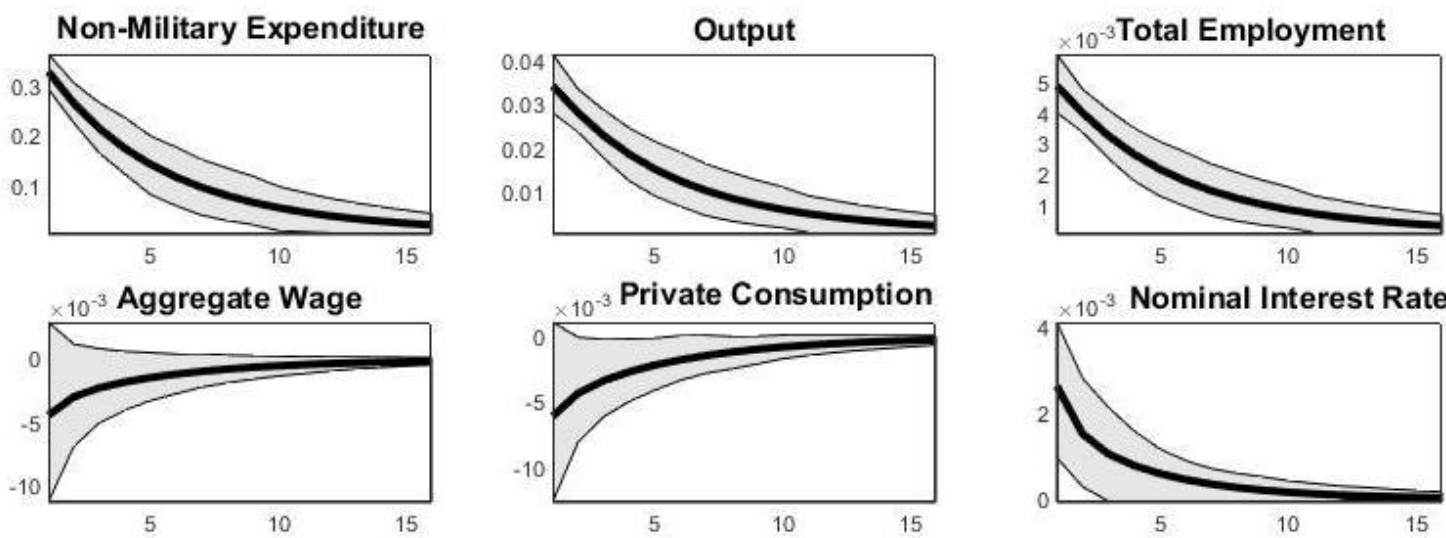

Figure A16. Non-military spending shock. Notes: The above graphs show the responses of the key variables together with their $95 \%$ confidence intervals. 
S1 (1954:Q3-1979:Q2)
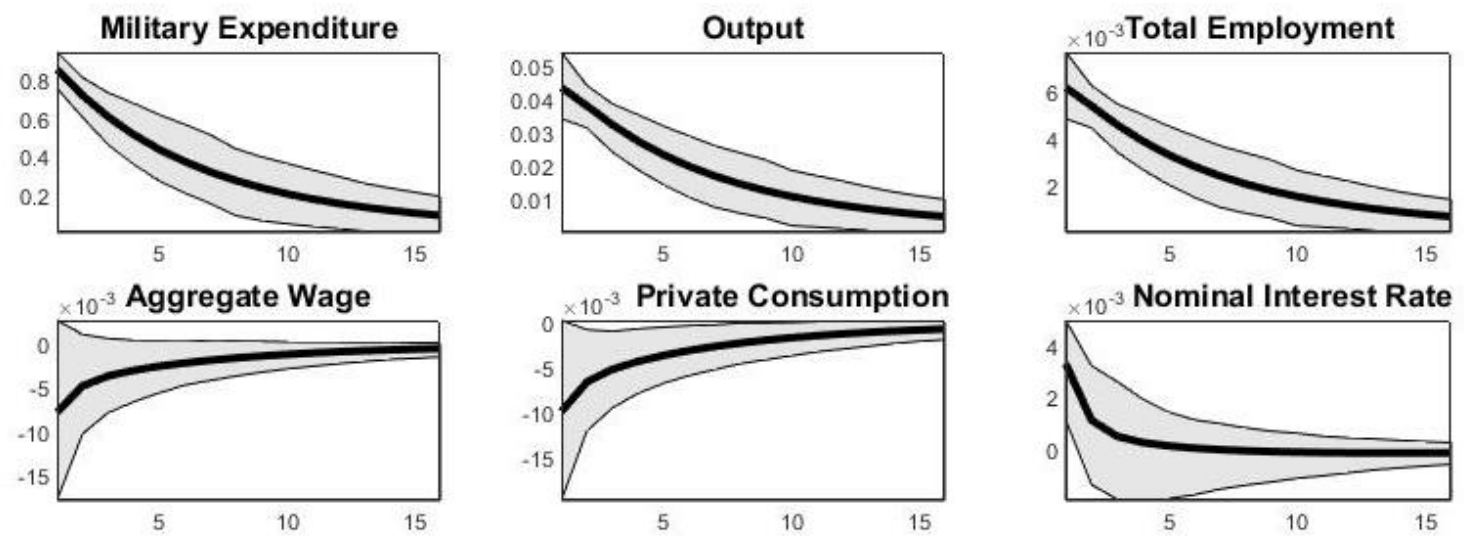

S2 (1983:Q1-2008:Q2)
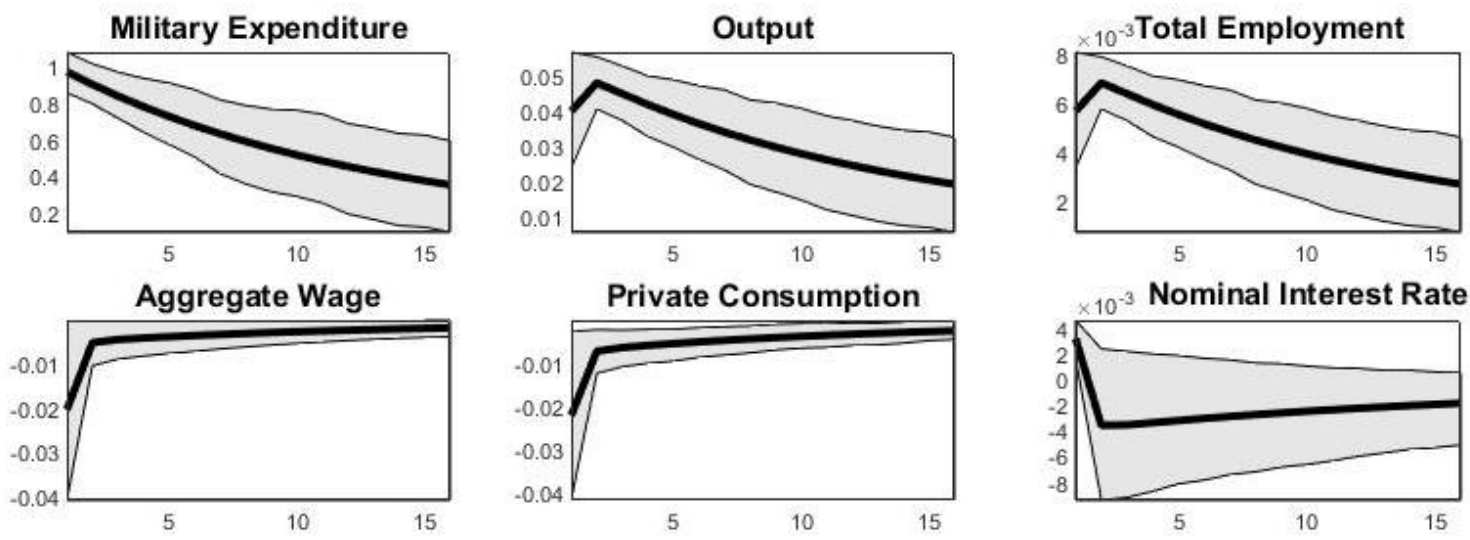

Figure A17. Military spending shock. Notes: The above graphs show the responses of the key variables together with their $95 \%$ confidence intervals. 


\section{Appendix F. Benchmark Model vs. DSGE-VARs}

Table A1. Comparison between the benchmark model and DSGE-VARs: model with total government spending.

\begin{tabular}{ccc}
\hline \multicolumn{3}{c}{ Sub-Sample 1 } \\
\hline & Marginal Log Density & Bayes Factor vs. Benchmark Model \\
\hline DSGE-VAR (1) & -189.714 & $\exp [27.449]$ \\
DSGE-BVAR(2) & -175.595 & $\operatorname{exp[13.331]~}$ \\
DSGE-BVAR (3) & -170.572 & $\exp [8.308]$ \\
DSGE-BVAR (4) & -171.844 & $\exp [9.579]$ \\
Benchmark Model & -162.264 & \\
\hline & Sub-Sample 2 & \\
\hline & Marginal Log Density & Bayes Factor vs. Benchmark Model \\
\hline DSGE-VAR (1) & -156.199 & $\operatorname{exp[-10.742]~}$ \\
DSGE-BVAR (2) & -154.106 & $\operatorname{exp[-12.835]~}$ \\
DSGE-BVAR (3) & -156.258 & $\operatorname{exp[-10.684]~}$ \\
DSGE-BVAR (4) & -171.844 & $\operatorname{exp[0.902]~}$ \\
Benchmark Model & -166.941 &
\end{tabular}

Notes: As in Bekiros and Paccagnini (2014), the DSGE-VARs are estimated with different numbers of lags (from 1-4). The tightness parameter is set equal to 0.5.

Table A2. Comparison between the benchmark model and DSGE-VARs: model with non-military and military expenditures.

\begin{tabular}{ccc}
\hline \multicolumn{3}{c}{ Sub-Sample 1 } \\
\hline & Marginal Log Density & Bayes Factor vs. Benchmark Model \\
\hline DSGE-VAR (1) & -372.712 & $\operatorname{exp[46.058]~}$ \\
DSGE-BVAR (2) & -368.905 & $\operatorname{exp[42.252]~}$ \\
DSGE-BVAR (3) & -368.800 & $\exp [42.146]$ \\
DSGE-BVAR (4) & -361.313 & $\operatorname{exp[34.659]~}$ \\
Benchmark Model & -326.653 & \\
\hline \multicolumn{4}{c}{ Sub-Sample 2 } \\
\hline & Marginal Log Density & Bayes Factor vs. Benchmark Model \\
\hline DSGE-VAR (1) & -347.561 & $\operatorname{exp[36.952]~}$ \\
DSGE-BVAR (2) & -329.899 & $\operatorname{exp[19.290]~}$ \\
DSGE-BVAR (3) & -336.235 & $\operatorname{exp[25.626]}$ \\
DSGE-BVAR (4) & -326.873 & $\operatorname{exp[0.000]}$ \\
Benchmark Model & -310.609 &
\end{tabular}

Notes: As in Bekiros and Paccagnini (2014), the DSGE-VARs are estimated with different numbers of lags (from 1-4). The tightness parameter is set equal to 0.5.

\section{References}

Albonico, Alice, Alessia Paccagnini, and Patrizio Tirelli. 2017. Great recession, slow recovery and muted fiscal policies in the U.S.. Journal of Economic Dynamics and Control 81: 140-61. [CrossRef]

Albonico, Alice, Alessia Paccagnini, and Patrizio Tirelli. 2019. Limited asset market participation and the euro area crisis: An empirical dsge model. Economic Inquiry 57: 1302-23. [CrossRef]

Ambler, Steve, and Alain Paquet. 1996. Fiscal spending shocks, endogenous government spending, and real business cycles. Journal of Economic Dynamics and Control 20: 237-56. [CrossRef]

Andrés, Javier, J. David López-Salido, and Edward Nelson. 2009. Money and the natural rate of interest: Structural estimates for the united states and the euro area. Journal of Economic Dynamics and Control 33: 758-76. [CrossRef] 
Baxter, Marianne, and Robert G. King. 1993. Fiscal policy in general equilibrium. The American Economic Review 83: 315-34.

Beidas-Strom, Samya, and Marco Lorusso. 2019. Do They Hurt? Macroeconomic Effects of Reforms on Three Diverse Oil Exporters: Russia, Saudi Arabia and the UK. IMF Working papers, Forthcoming.

Bekiros, Stelios D., and Alessia Paccagnini. 2014. Bayesian forecasting with small and medium scale factor-augmented vector autoregressive DSGE models. Computational Statistics \& Data Analysis 71: 298-323.

Bilbiie, Florin O., Andre Meier, and Gernot J. Muller. 2008. What accounts for the changes in U.S. fiscal policy transmission? Journal of Money, Credit and Banking 40: 1439-70. [CrossRef]

Blanchard, Olivier, and Roberto Perotti. 2002. An empirical characterization of the dynamic effects of changes in government spending and taxes on output. The Quarterly Journal of Economics 117: 1329-68. [CrossRef]

Bohn, Henning. 1998. The behavior of us public debt and deficits. The Quarterly Journal of Economics 113: 949-63. [CrossRef]

Brooks, Stephen P., and Andrew Gelman. 1998. General methods for monitoring convergence of iterative simulations. Journal of Computational and Graphical Statistics 7: 434-55.

Calvo, Guillermo A. 1983. Staggered prices in a utility-maximizing framework. Journal of Monetary Economics 12: 383-98. [CrossRef]

Christiano, Lawrence, Martin Eichenbaum, and Sergio Rebelo. 2011. When is the government spending multiplier large? Journal of Political Economy 119: 78-121. [CrossRef]

Coenen, Günter, Roland Straub, and Mathias Trabandt. 2012. Fiscal policy and the great recession in the euro area. American Economic Review 102: 71-76. [CrossRef]

Corsetti, Giancarlo, André Meier, and Gernot J. Müller. 2012. Fiscal stimulus with spending reversals. Review of Economics and Statistics 94: 878-95. [CrossRef]

Del Negro, Marco, and Frank Schorfheide. 2004. Priors from general equilibrium models for vars. International Economic Review 45: 643-73. [CrossRef]

Del Negro, Marco, and Frank Schorfheide. 2008. Forming priors for dsge models (and how it affects the assessment of nominal rigidities). Journal of Monetary Economics 55: 1191-208. [CrossRef]

Enders, Zeno, Gernot J. Müller, and Almuth Scholl. 2011. How do fiscal and technology shocks affect real exchange rates?: New evidence for the united states. Journal of International Economics 83: 53-69. [CrossRef]

Fatás, Antonio, and Ilian Mihov. 2001. The Effects of Fiscal Policy on Consumption and Employment: Theory and Evidence. London: Centre for Economic Policy Research, vol. 2760.

Fatás, Antonio, and Ilian Mihov. 2003. The case for restricting fiscal policy discretion. The Quarterly Journal of Economics 118: 1419-47. [CrossRef]

Forni, Lorenzo, Libero Monteforte, and Luca Sessa. 2009. The general equilibrium effects of fiscal policy: Estimates for the euro area. Journal of Public economics 93: 559-85. [CrossRef]

Galí, Jordi, David Lopez-Salido, and Javier Valles. 2007. Understanding the effects of government spending on consumption. Journal of the European Economic Association 5: 227-70. [CrossRef]

Galí, Jordi, and Roberto Perotti. 2003. Fiscal policy and monetary integration in europe. Economic Policy 18: 533-72. [CrossRef]

Iskrev, Nikolay. 2010. Local identification in dsge models. Journal of Monetary Economics 57: 189-202. [CrossRef]

Kormilitsina, Anna, and Sarah Zubairy. 2018. Propagation mechanisms for government spending shocks: A Bayesian comparison. Journal of Money, Credit and Banking 50: 1571-616. [CrossRef]

Leeper, Eric M., Todd B. Walker, and Shu-Chun S. Yang. 2010. Government investment and fiscal stimulus. Journal of Monetary Economics 57: 1000-12. [CrossRef]

Linnemann, Ludger, and Andreas Schabert. 2006. Productive government expenditure in monetary business cycle models. Scottish Journal of Political Economy 53: 28-46. [CrossRef]

Lorusso, Marco, and Luca Pieroni. 2017. The effects of military and non-military government expenditures on private consumption. Journal of Peace Research 54: 442-56. [CrossRef]

Perotti, Roberto. 2005. Estimating the Effects of Fiscal Policy in OECD Countries. Proceedings. Available online: https:/ / econpapers.repec.org/article/fipfedfpr/y_3a2005_3ax_3a9.htm (accessed on 15 July 2019). [CrossRef]

Pieroni, Luca, Giorgio d'Agostino, and Marco Lorusso. 2008. Can we declare military keynesianism dead? Journal of Policy Modeling 30: 675-91. [CrossRef] 
Rabanal, Pau, and Juan F. Rubio-Ramírez. 2001. Nominal versus Real Wage Rigidities: A Bayesian Approach. Working paper, Federal Reserve Bank of Atlanta, Atlanta.

Ramey, Valerie A., and Matthew D. Shapiro. 1999. Costly Capital Reallocation and the Effects of Government Spending. NBER Working papers, National Bureau of Economic Research, Inc., Cambridge.

Ramey, Valerie A., and Sarah Zubairy. 2018. Government spending multipliers in good times and in bad: Evidence from us historical data. Journal of Political Economy 126: 850-901. [CrossRef]

Ramey, Valerie A. 2011. Identifying government spending shocks: It's all in the timing. The Quarterly Journal of Economics 126: 1-50. [CrossRef]

Smets, Frank, and Rafael Wouters. 2007. Shocks and frictions in us business cycles: A Bayesian dsge approach. American Economic Review 97: 586-606. [CrossRef]

Taylor, John B. 1993. Discretion versus policy rules in practice. Carnegie-Rochester Conference Series on Public Policy 39: 195-214.

(C) 2019 by the authors. Licensee MDPI, Basel, Switzerland. This article is an open access article distributed under the terms and conditions of the Creative Commons Attribution (CC BY) license (http://creativecommons.org/licenses/by/4.0/). 